\title{
Intelligent Injection Molding on Sensing, Optimization, and Control
}

\author{
Peng Zhao $\mathbb{D}^{1,2}$ Jianfeng Zhang, ${ }^{1,2}$ Zhengyang Dong, ${ }^{1,2}$ Junye Huang, ${ }^{1,2}$ Hongwei Zhou, ${ }^{3}$ \\ Jianzhong Fu, ${ }^{1,2}$ and Lih-Sheng Turng $\mathbb{D D}^{4,5}$ \\ ${ }^{1}$ The State Key Laboratory of Fluid Power and Mechatronic Systems, College of Mechanical Engineering, Zhejiang University, \\ Hangzhou 310027, China \\ ${ }^{2}$ Key Laboratory of 3D Printing Process and Equipment of Zhejiang Province, College of Mechanical Engineering, \\ Zhejiang University, Hangzhou 310027, China \\ ${ }^{3}$ Tederic Machinery Co., Ltd., Hangzhou 311224, China \\ ${ }^{4}$ Department of Mechanical Engineering, University of Wisconsin-Madison, Madison, WI 53706, USA \\ ${ }^{5}$ Wisconsin Institute for Discovery, University of Wisconsin-Madison, Madison, WI 53715, USA
}

Correspondence should be addressed to Peng Zhao; pengzhao@zju.edu.cn and Lih-Sheng Turng; turng@engr.wisc.edu

Received 1 August 2019; Accepted 25 November 2019; Published 31 March 2020

Academic Editor: Federico Carosio

Copyright (c) 2020 Peng Zhao et al. This is an open access article distributed under the Creative Commons Attribution License, which permits unrestricted use, distribution, and reproduction in any medium, provided the original work is properly cited.

Injection molding is one of the most significant material processing methods for mass production of plastic products. It is widely used in various industry sectors, and its products are ubiquitous in our daily life. The settings and optimization of the injection molding process dictate the geometric precision and mechanical properties of the final products. Therefore, sensing, optimization, and control of the injection molding process have a crucial influence on product quality and have become an active research field with abundant literature. This paper defines the concept of intelligent injection molding as the integral application of these three procedures-sensing, optimization, and control. This paper reviews recent studies on methods for the detection of relevant physical variables, optimization of process parameters, and control strategies of machine variables in the molding process. Finally, conclusions are drawn to discuss future research directions and technologies, as well as algorithms worthy of being explored and developed.

\section{Introduction}

The Society of the Plastics Industry (SPI) has reported that, in the United States, the plastics industry is the third largest manufacturing industry. In 2017, the US plastics industry accounted for $\$ 432.32$ billion in annual shipments and directly employed nearly one million people [1]. Hence, the plastics industry has a large contribution to the nation's economy. Plastics are now among the most widely used materials and their use covers the entire spectrum of industries worldwide [2]. Injection molding is regarded as the most important and efficient process used to manufacture plastic products. It accounts for approximately $80 \%$ of the plastic merchandise in the modern plastics industry [2], and as such, it is one of the important pillars of the manufacturing industry. As a highly complicated process, plastic injection molding can be divided into three stages: filling, packing, and cooling. During the entire process, the polymer is subject to large and dynamic changes in pressure and temperature. The whole process is complicated because the process variables are strongly coupled and hard to analyze accurately. For now, manufacturing of qualified products by injection molding still mainly relies on manual operation and trial-and-error methods [3-5]. Obviously, this traditional approach has disadvantages of low production efficiency, poor reliability and repeatability, and dependence on prior experience. Therefore, it is imperative and crucial to develop an advanced injection molding method that is science based and technology oriented. 
Recently, much attention has been focused on intelligent (smart) manufacturing, which represents an in-depth integration of next-generation artificial intelligence (AI) technology and advanced manufacturing technology. It runs through every link in the full life cycle of design, production, product, and service [6]. Intelligent injection molding refers to the production process that employs AI technology-such as extracting information from production, computer optimization methods, and control strategies - to develop an online production optimization system. Through the comprehensive use of sensing, optimization, and control methods, the intelligent injection molding production process can increase production efficiency and product quality.

During the production process, when material and mold are preselected, an intelligent injection molding method is required to obtain high quality and stable production. As shown in Figure 1, intelligent injection molding contains three phases-sensing, optimization, and control-all of which are interrelated. Process sensing is first needed to realize real-time detection of variables from the injectionmolding process and further on to diagnose and guide the manufacturing process. Moreover, optimal process parameters should be determined by process optimization since it is the key to obtaining high-quality injection molded products with high precision. Finally, sufficient machine control accuracy and repeatability-which means robust control over machine parameters-are required. Furthermore, advanced control strategies will help to conserve energy in manufacturing [7]. Integrating these three phases into an effective online quality control model, which is the section in the dotted-line frame in Figure 1, is one of the major goals of intelligent injection molding. It has attracted extensive attentions from many researchers in the field of injection molding.

In a 2005 review article, injection molding control [8] after process setup was classified into three levels-machine control, process control, and quality control. Due to the lack of quality sensors and the process and quality relationship model, there is a potential opportunity for advancement in the optimization and control of the product quality in injection molding. Moreover, with further development of science and technology in injection molding, and the fact that there has been very little review of process sensing, this paper aims to review and summarize the research on intelligent injection molding in recent years. It will focus on sensing, optimization, and control so that readers will be able to obtain useful information and an overview of the intelligent injection molding process. This paper is outlined as follows. Section 1 provides a brief introduction of intelligent injection molding. Sections 2, 3, and 4 discuss sensing, optimization, and control methods for the injection molding process and present up-to-date developments in these fields. The last section provides a summary of and future directions for intelligent injection molding.

\section{Process Sensing}

The sensing of the injection molding process is focused on the temperature, pressure, position, speed, etc., which reflect the physical state of the process. Temperature and pressure are the two fundamental physical variables that are the most important in the injection molding process. Furthermore, among various sensing technologies, temperature and pressure sensors are the most well developed and the most widely utilized. By means of sensing the temperature and pressure, one can obtain abundant information about the mold and polymer melt. With continuing technology development, some new methods have emerged in the field of injection molding. Some of them are capable of characterizing more variables besides temperature, pressure, position, and speed. This section will briefly introduce the conventional and emerging methods used in injection molding processes and the up-to-date research progress. Finally, a conclusion and analysis will be put forward and discussed.

2.1. Conventional Methods. Temperature and pressure are the most important variables in the injection molding process. As such, they have received the most attention. Therefore, traditional pressure and temperature sensors are maturely developed and have been the most important tools in measuring the melt state and in characterizing product quality (cf. Figure 2(a)).

2.1.1. Pressure Measurement. Pressure sensors come in mainly two types-resistance and piezoelectricity-which generate resistance changes and voltage changes, respectively, in response to the different pressure levels to characterize the value of the pressure. Commercial pressure sensors have advanced rapidly. In recent years, commercial pressure sensors have been widely used to study the correlation between melt pressure and various parameters of the injection molding process [12-15]. Furthermore, pressure sensors have also been utilized to study the correlation between the cavity pressure curve during the injection/ packing stage and the final deformation of the molded part [16]. The results indicated that the pressure difference of the melt at two locations along the radial flow path was related to the part deformation, which could then be used to characterize the warpage of the molded product. Mao et al. [17] proposed a novel automatic feature learning method using cavity pressure data. The results showed that the proposed method could achieve higher classification accuracies and offer more optimal solutions for process monitoring. Based on these studies, online cavity pressure curves can be used to characterize injection process parameters and product quality. Since the value of cavity pressure that the pressure sensor detects usually turns out to be a one-dimensional (1D) value (in the normal direction), Heinle and Drummer [18] therefore proposed a standard three-way force sensor, which was stiffly connected to the measurement element in the cavity to measure the $3 \mathrm{D}$ force in a cavity. However, installing direct pressure sensors sometimes introduces product defects in the form of surface sensor marks.

In recent studies, researchers have put forward some alternative methods for cavity pressure measurements in order to maintain the integrity of the part and mold. Gim et al. [10] installed indirect pressure sensors under the lens 
Process parameters:

More than 40 parameters, such as injection parameters, pressure holding parameters, and cooling parameters.

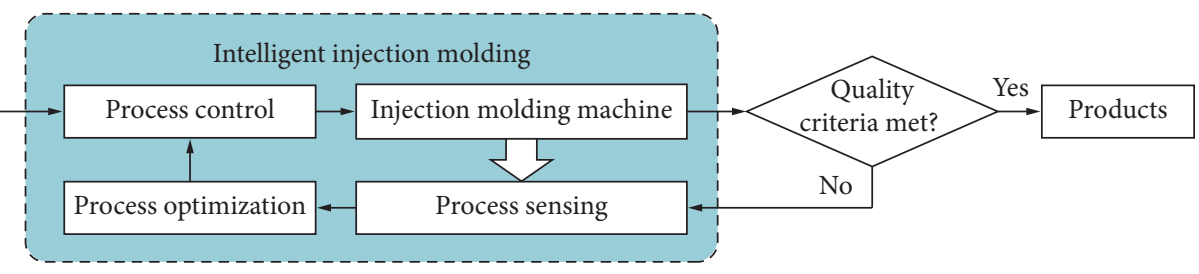

FIGURE 1: Schematic of an intelligent injection molding process.

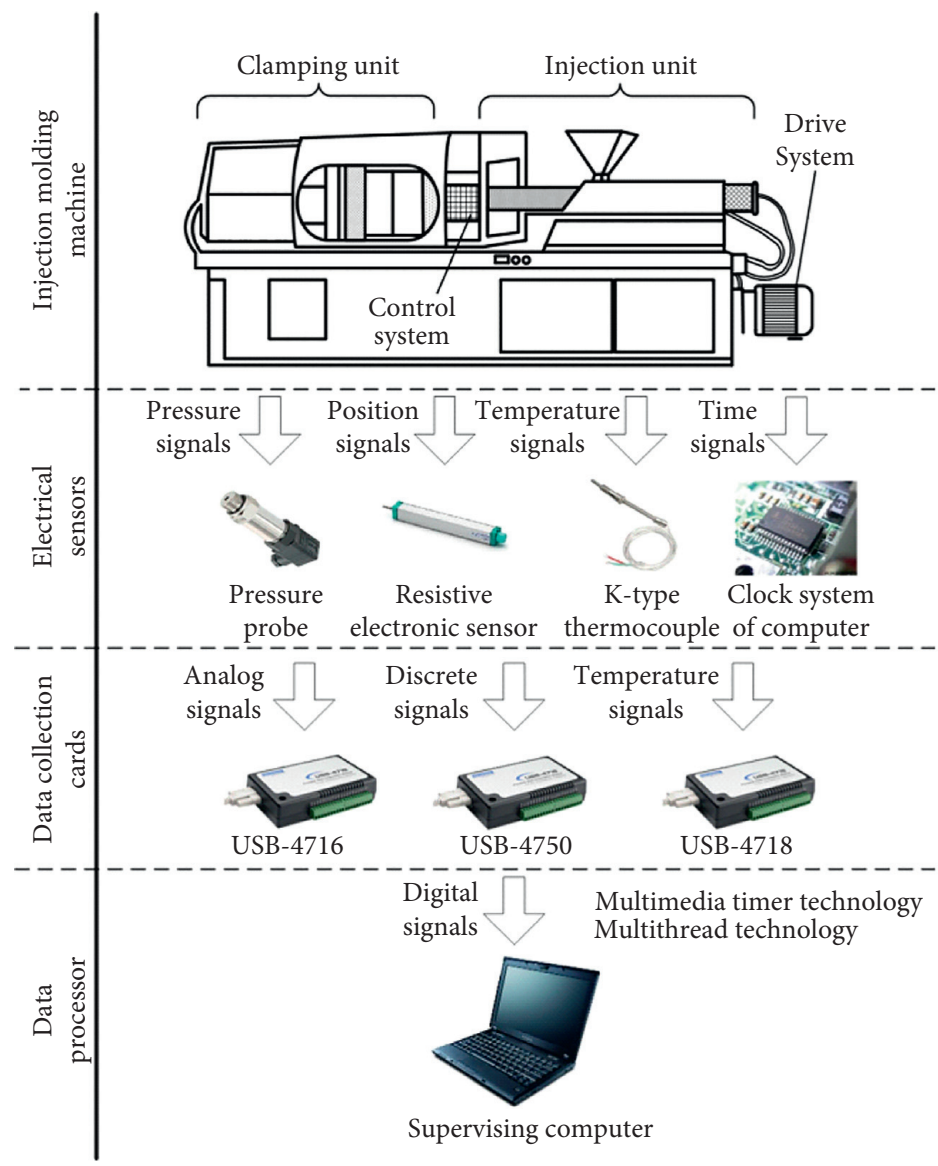

(a)
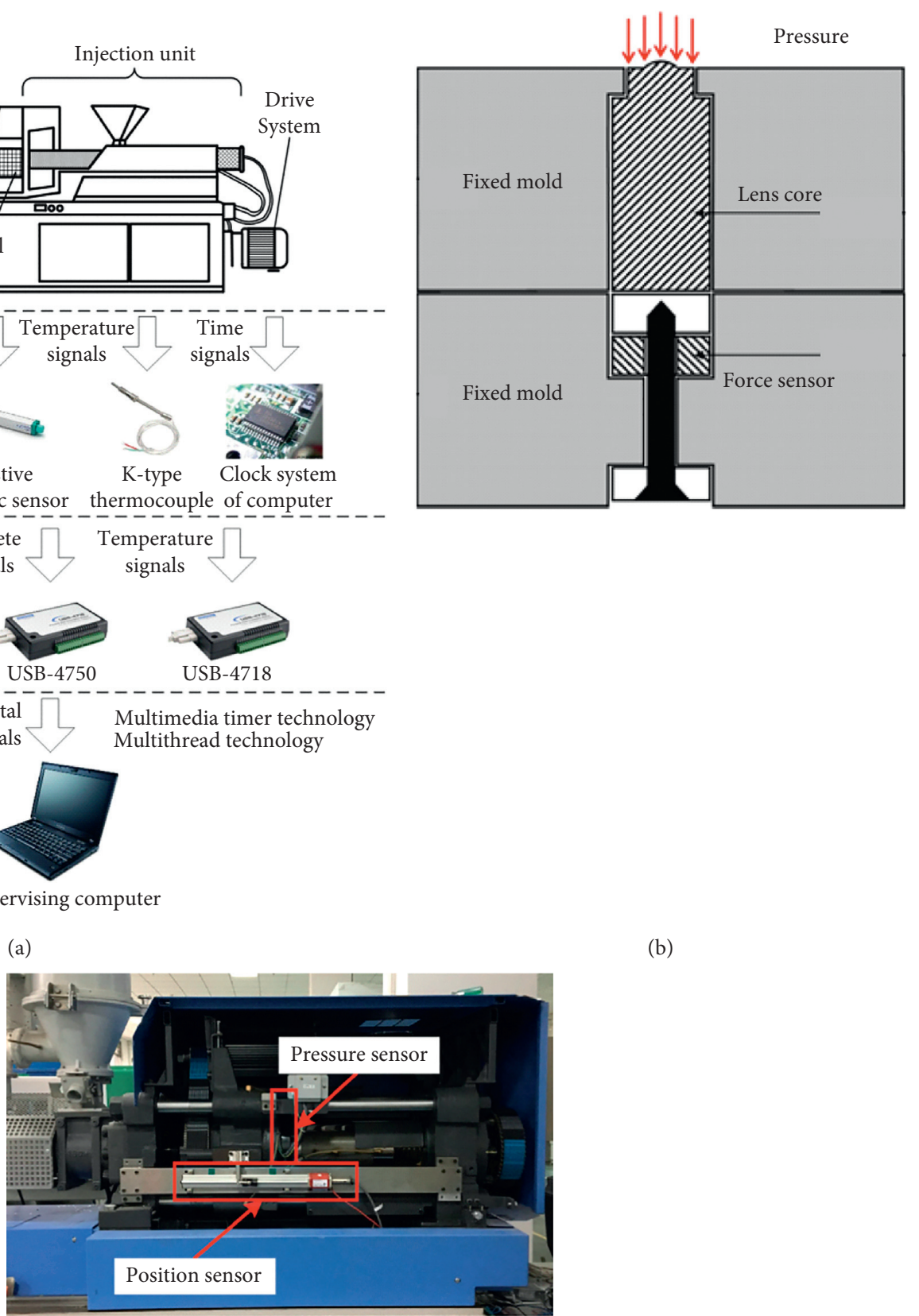

(b)

(c)

FIGURE 2: (a) Conventional sensors used in online sensing of injection molding process [9]. (b) Illustration of an indirect pressure sensor [10]. (c) The injection molding machine with respect to position and pressure sensors equipped [11]. 
core to monitor filling imbalance and short shots without causing product defects (cf. Figure 2(b)). Tsai and Lan [19] investigated the correlation between melt pressure and cavity pressure in different runner positions and identified the runner position where the local runner pressure represented the cavity pressure. In addition, product quality can be monitored by installing sensors at different runner positions. Guan and Huang [20] used a surface strain sensor and pressure sensors installed at the cavity and surface of the mold, respectively, and found that the cavity pressure was proportional to the mold surface strain through a data-based regression method. Using this correlation, the precise cavity pressure distribution could be obtained indirectly via mold surface strain data. Furthermore, some quality monitoring methods using other pressure sensors have also been proposed. Zhang et al. [21] proposed a statistical quality monitoring method for injection molding, which used only hydraulic pressure and screw position data obtained from built-in machine sensors. With the present method, the rate of successful fault detection was excellent. Zhou et al. [11] established a quality prediction model based on polymer melt properties to monitor product weigh variation online. The pressure integral, which was obtained by using the machine's built-in injection pressure sensor, was used as an effective process variable to predict product weight variation (cf. Figure 2(c)).

2.1.2. Temperature Measurement. Thermocouples and infrared temperature sensors are the two most common sensors for online temperature detection in the injection molding process. A thermocouple is a kind of sensor that transforms thermal potential difference into electrical potential difference. According to the selected conductive material, it can be classified into S, B, K, E, T, and J types. Considering the cost and the working environment, J-type and K-type thermocouples are usually used. Thermocouples are widely used in the development and operation of rapid heat cycle molding (RHCM) [22-27], which is a process that rapidly changes the surface temperature of the mold during the injection and cooling stages for the purpose of producing products with special features, such as high-gloss surfaces, without prolonging the cycle time. Temperature sensors can feasibly monitor the temperature of the mold, cavity surface, and heat transfer medium (e.g., the coolant).

However, when detecting the melt temperature, the thermocouple can only measure the contact temperature at the contact point between the material (mold or melt) and the sensor, and this measurement is unlikely to be characteristic of the bulk temperature of the melt. Johnston et al. [28] developed an analysis that used the data from an in-mold thermocouple to predict the bulk melt temperature of a plastic. The heat flux through the mold steel was taken into account to calculate the overall melt temperature and the result was verified by an infrared (IR) temperature sensor. In another study, by measuring the instantaneous melt temperature, Yang et al. [29] investigated the crystallization and solidification kinetics during injection molding, which represented another usage of a thermocouple in injection molding.
Injection molding is known as a process that is accompanied by drastic changes in both temperature and pressure. In order to reveal more online process information during injection molding, the comprehensive use of various sensors has become a commonly used research approach. Gao et al. [30, 31] obtained online melt viscosity and speed through the combined use of a variety of sensors (thermocouples, infrared temperature sensors, pressure sensors, and multitemperature and pressure sensors, cf. Figure 3). The viscosity and speed were calculated from the measured values from those sensors. Mendibil et al. [32] monitored pressure and temperature transducers located in a runner system and microfeatured cavity and further achieved online quality inspection and quality test results from a confocal microscope.

2.2. Emerging Methods. To obtain melt information other than temperature and pressure, some emerging methods have been employed for injection molding process sensing. Such emerging methods include ultrasound, visualization molds, X-ray computed tomography, capacitive sensors, and magnetic levitation detection. These methods will be introduced as follows.

2.2.1. Ultrasound. Ultrasound waves are mechanical waves whose frequencies are greater than $20 \mathrm{kHz}$ [33]. Ultrasonic technology is a promising method for the characterization of polymer processes as it can be applied in real time and online, as well as being nondestructive and environmentally friendly [34-36]. Ultrasound waves reflect at the surface of the media, and the attenuation and speed of the waves change according to the properties of the media. By studying the relationship between the attenuation and speed of ultrasound pulse-echoes and the physical properties of the polymer, this method has been applied in many studies for offline detection of injection molded parts [37,38]. Similarly, ultrasound can be applied online for quality detection during the production process [39].

Based on the principle of the ultrasonic method, online detection of the material in the barrel and nozzle during injection molding can be realized. For example, the solid bed to melt pool ratio has been quantified using a noninvasive ultrasound system based on reflection measurements [40]. Automated analyses of the reflected pulses were also realized, which means that the plasticization process can be monitored online at different axial positions along the barrel. Praher and Steinbichler [41] measured the clearance between screw and barrel in the plasticization unit of an injection molding machine, where the wear status of the tribomechanical screw-barrel system and unsuitable process conditions could be detected. Moreover, besides the melt content and melt condition in the plasticizing process being detected by ultrasound, a noninvasive ultrasound tomography system was also proposed by Praher et al. [42, 43]. An ultrasound transmitter and five ultrasound receivers were employed, and five individual sound paths through the polymer melt were achieved (cf. Figure 4(a)). Thus, the temperature distribution in the polymer melt could be 

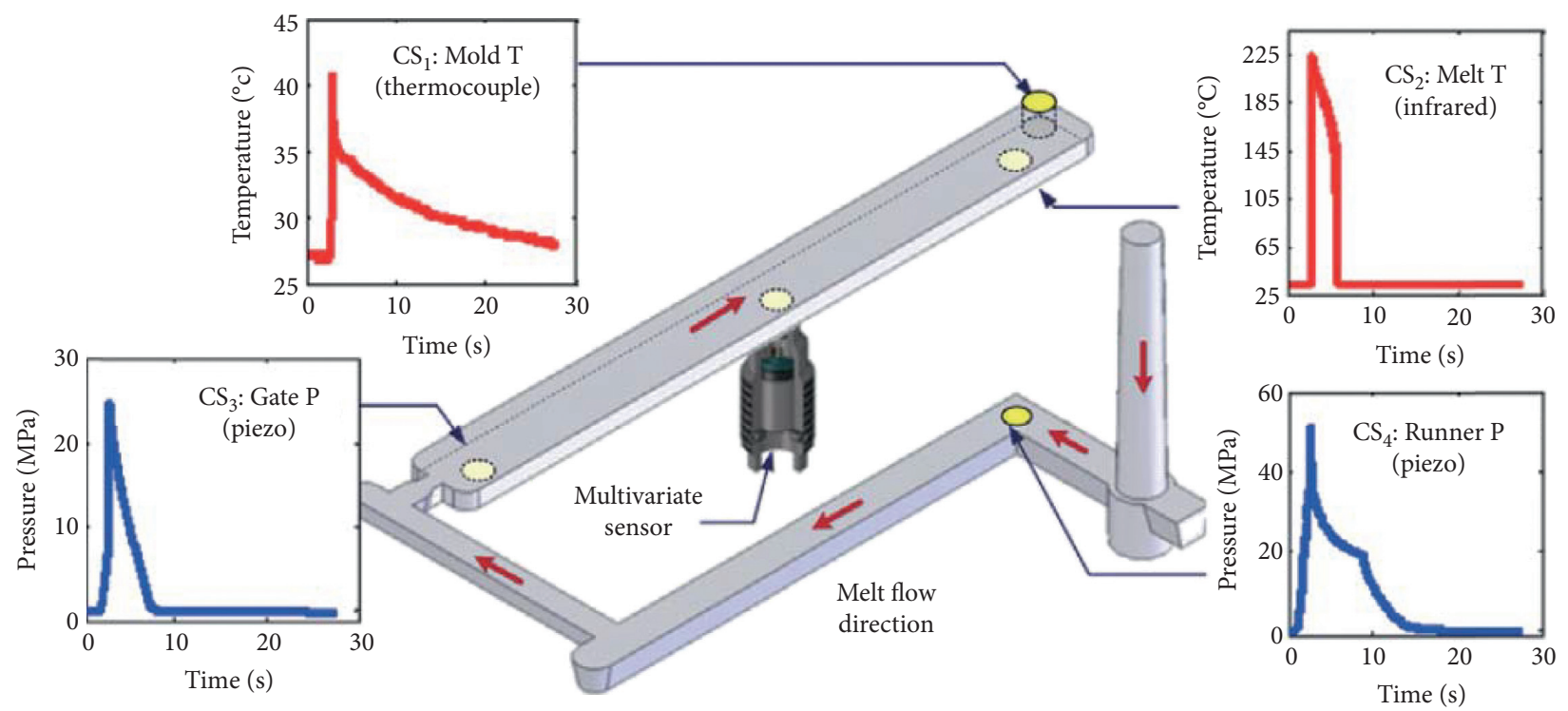

Figure 3: Process instrumentation using commercial sensors (CS) for pressure (P) and temperature (T), as well as a developed multivariate sensor (MVS) within an injection mold cavity [30].
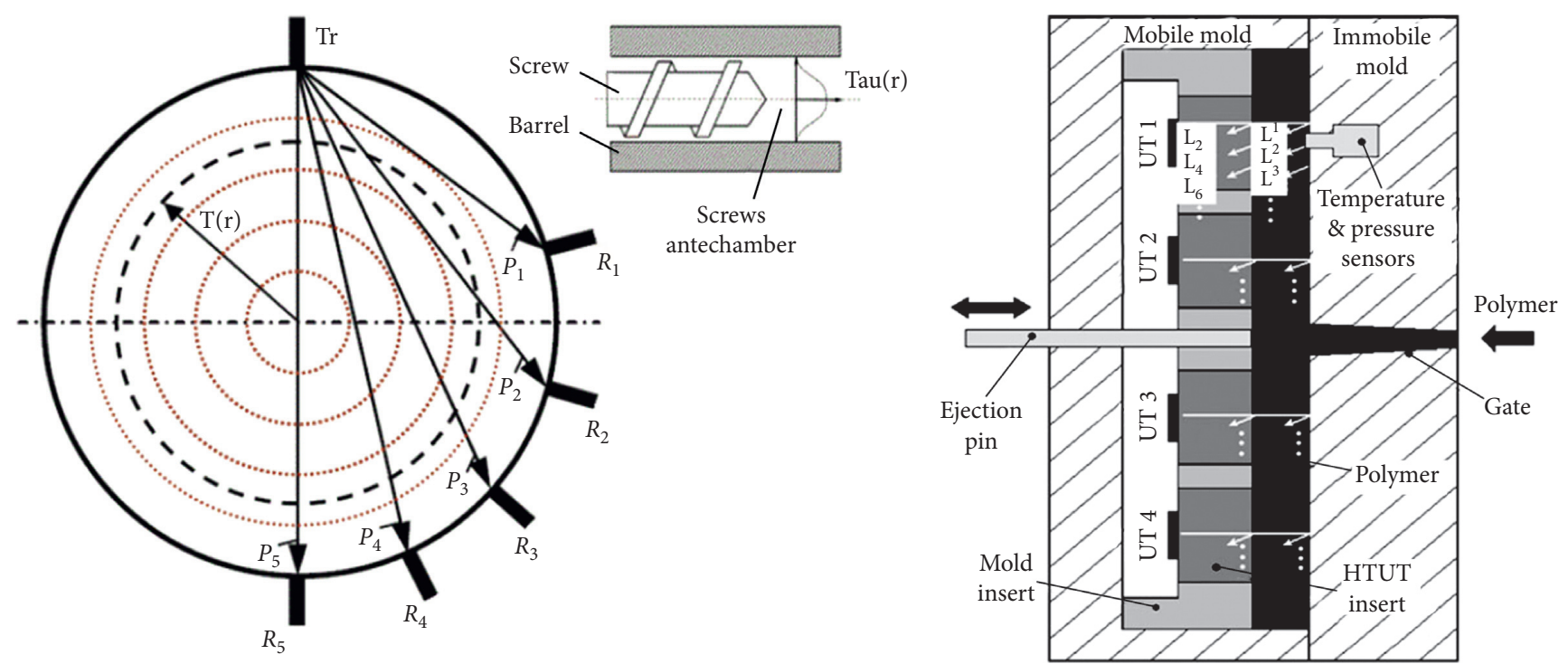

..... Assumed isotherms for temperature reconstruction

- - - Radial-symmetrical temperature distribution $\mathrm{T}(\mathrm{r})$

Tr ultrasonic transmitter

R1-R5 ultrasonic receiver

P1-P5 sound paths

(a)

(b)

Figure 4: (a) Positions of the ultrasound transducers and resulting sound paths through the concentric ring segments used in ultrasound tomography [43]. (b) A cross-sectional view of an in-mold detection system [44].

calculated by analyzing the transmission times of the ultrasound pulses through different sound paths. Ultrasound probe design strategies were also discussed, given that conventional ultrasound transducers cannot endure high temperature environments, such as the injection barrel.

Ono et al. made a great contribution in this area. Specifically, a high temperature ultrasonic transducer was invented and applied in microinjection molding [45], coinjection molding [46], and gas-assisted injection molding processes [47] for online polymer characterization. By installing high temperature ultrasound transducers at the nozzle location, $\mathrm{Wu}$ et al. $[48,49]$ revealed the flow characteristics of the polymer melt and the flow conditions at the nozzle. The melt flow characteristics at the nozzle, including 
the dynamic flow speed and density of the polymer melt, can be monitored online.

The detection of in-mold information by ultrasound reveals abundant information about the process and the properties of the melt during the injection molding process. The microcellular injection molding (MIM) process was also characterized by an in situ ultrasonic method [50] (cf. Figure 5). In this study, cell size, surface roughness, and skin layer thickness of the products were characterized by ultrasonic echo signal. Moreover, the detection of longitudinal waves characterized the injection process data and polymer morphological changes in real time, including the melt front arrival time, injection time, filling and packing stages, polymer solidification process, and morphological changes in the polymer crystallization $[44,51]$. Shear waves in real time diagnosed Young's modulus and shear storage modulus, as well as the anisotropic properties of the polymer in the injection molding process [44] (cf. Figure 4(b)). Although the methods and theory used here are quite similar to those used to detect plasticization, this part of the measurement is an online, nonisothermal process that is quite difficult to implement. The data is difficult to analyze as well.

Our research group proposed an ultrasonic methodology to measure cavity pressure during the injection molding process via the Gaussian process $[9,52]$. Recently, we employed an ultrasonic method to measure the stress on the tie bars of an injection molding machine, therefore monitoring the service situation of the machine $[53,54]$. We also established a physical model to estimate the correlation between the cavity pressure and stress on the tie bars and as such achieved an indirect measurement of the cavity pressure via the stress on the tie bars [55].

2.2.2. Visualization Molds. Because the molten polymer behavior during the injection molding process is carried out in a closed cavity, the molding process cannot be observed by the naked eye. Therefore, researchers often develop a visualization mold combined with a high-speed camera to observe the molding process [56-60]. Guerrier et al. [56, 57] developed a visualization mold by replacing part of the mold steel with glass to observe and verify the accuracy of a $3 \mathrm{D}$ numerical simulation of the injection molding process carried out by computer molding and obtained ideal results (cf. Figure 6). Jong et al. [58] added aluminum glitter powder to the melt to observe and track the flow trajectory of the particles in the melt to observe the fountain flow effect at the melt front. Jiang et al. also developed a visualized experimental device to observe the flow of the polymer melt of coinjection molding and ultrasonic-assisted injection molding process $[59,60]$.

2.2.3. X-Ray Computed Tomography. For injection molding parts, the researchers paid most attention to the mechanical properties of the products. However, the surface replicability and internal structure of the parts could be more concerned in a considerable part of the situation. These properties of the products have yet been difficult to be characterized and there is rarely related research. The application of computed tomography (CT) in industry is rapidly increasing. CT scanning is capable of evaluating the voxel-based and surface-based characteristic [61]. As being voxel based, it can serve as a visualization method and give the images of the inner structure of the work pieces. It is widely applied in the defect detection and fiber orientation distribution observation [62-64] of the injection molded parts (cf. Figure 7(a)). As being surface based, such as digitization and dimensional metrology [65], it can measure the surface profile and deviation of injection molded parts (cf. Figure 7(b)). Certainly, it requires accuracy and traceability. In addition, CT scanning still has its limitations; the faster cycle time and better economy need to be achieved for wider manufacturing applications.

2.2.4. Capacitive Sensors. Capacitance is a useful physical phenomenon for sensor design. It has been successfully applied for measuring the distance, area, volume, force, humidity, etc., in industry [66]. If two metal plates can be separately installed on the two mold halves and isolated from each other, they can form the two electrodes of a capacitor. Such a capacitive sensor for the measurements of the melt front position and melt front velocity has been proposed for injection molding process monitoring [66-69]. Due to the filling of the polymer melt, the capacitance between the two electrodes changes, resulting in a change of voltage on the capacitor. The principle and installation scheme of a capacitive transducer are shown in Figure 8(a). The ratio of polymer to air causes variations in the dielectric properties of the capacitor, further resulting in a change of voltage on the electrodes.

Capacitive sensors can detect not only the polymer melt front position and melt flow rate [69], but also the start and end of mold filling, the time of gate freezing, and overpacking [66]. The sensor outputs can be further correlated to online part weight prediction and also the measurement of the part solidification rate [68]. Combined with data-based regression analysis, this type of sensor could be used for online monitoring, part weight prediction, and check-ring failure detection for injection molding [67].

Based on the same principles as dielectrics, a rheodielectric sensor, also called a planar capacitor sensor, has been developed with interdigitated electrodes deposited on the surface of the substrate adjacent to the dielectric material [70]. Interdigitated electrodes are electrode strips arranged like the interlocking fingers of two hands folded together (cf. Figures $8(\mathrm{~b})$ and $8(\mathrm{c}))$. This kind of sensor can be mounted on the cavity surface, where the voltage variation on the electrodes reflects the dielectric constant of the material, which is related to the shear stress and orientation of the material [71-73]. Therefore, the planar capacitor sensor is able to measure the shear stress and orientation of the material in the injection molding process.

2.2.5. Magnetic Levitation. Quality detection of final parts is an important component of injection molding production. In the field of materials science, there are several characterization methods including wide angle X-ray diffraction 

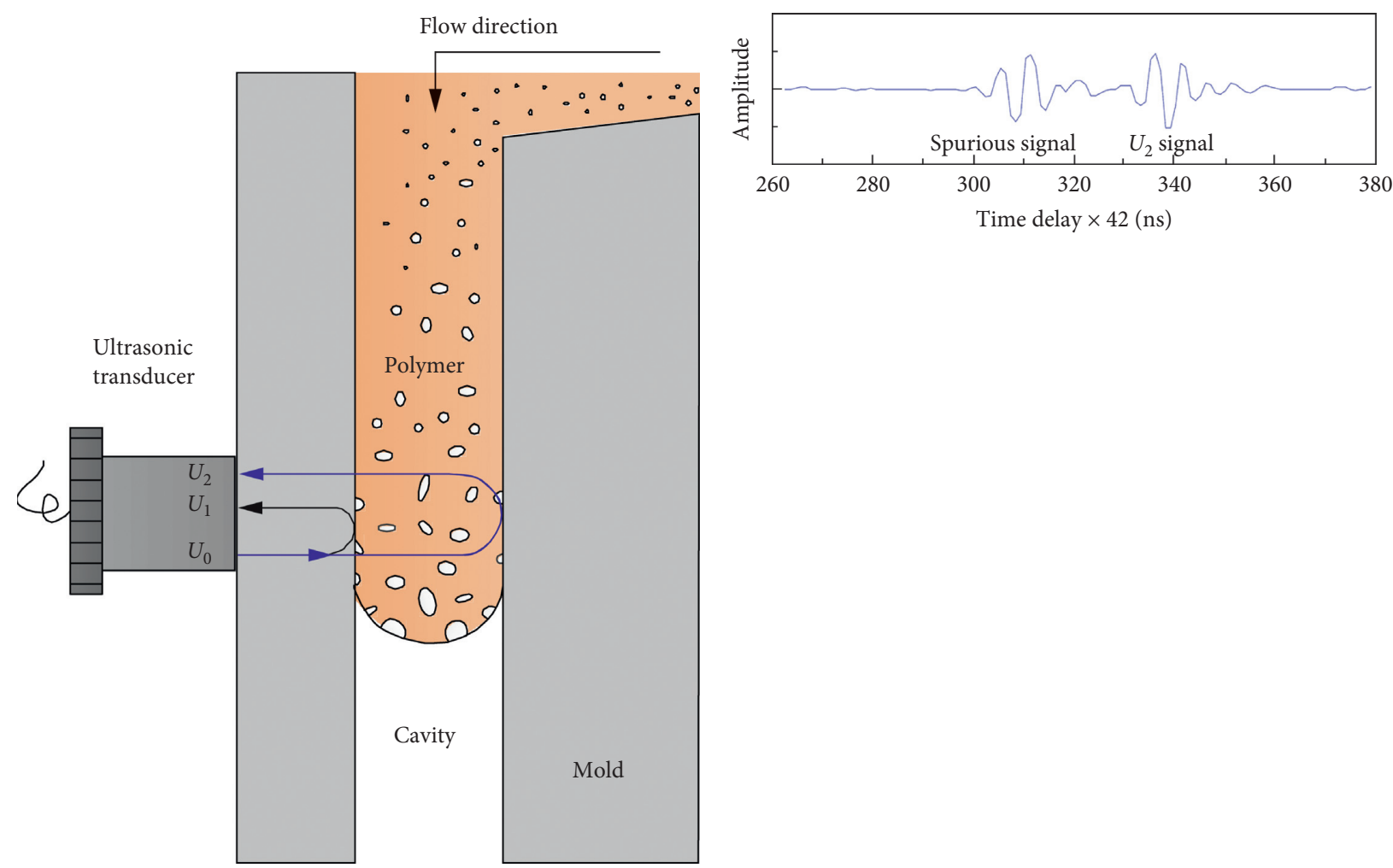

(a)

(b)

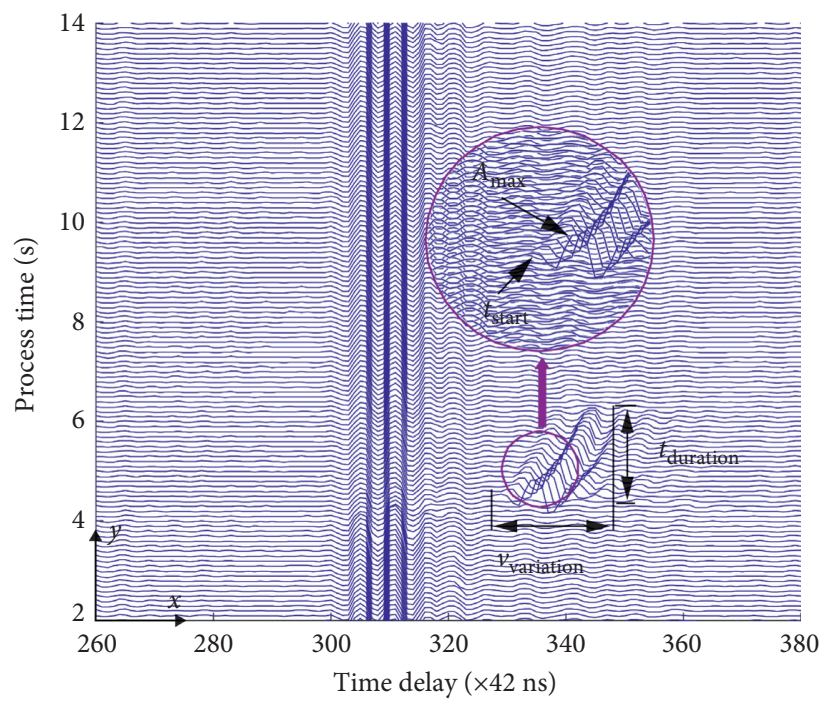

(c)

Figure 5: An ultrasonic pulse-echo measurement method for online characterization of (a) a cross-sectional schematic view of a mold with an ultrasonic transducer, (b) a typical single signal received with the transducer, and (c) typical U2 ultrasonic signals over a microcellular injection molding (MIM) process cycle [50].

(WAXD) [74-79], nanocalorimetry [80], and X-ray tomography $[62,63]$. These methods are generally and widely utilized for measuring physical properties of final products. They have excellent characterization accuracy, but the cost of equipment is usually very high.

A magnetic levitation detection method has been proposed by Mirica and colleagues in 2009 for measuring density [81], which also is called the MagLev method. The device consists of two identical permanent magnets set $45 \mathrm{~mm}$ apart, with identical poles facing each other. The sample is immersed in paramagnetic media and is then levitated at an equilibrium position along the centerline of the device (cf. Figure 9(a)). According to the levitation height, the density of the sample can be calculated. The accuracy of the device is estimated as $0.0002 \mathrm{~g} / \mathrm{cm}^{3}$. Many researchers focus on developing MagLev technology and 

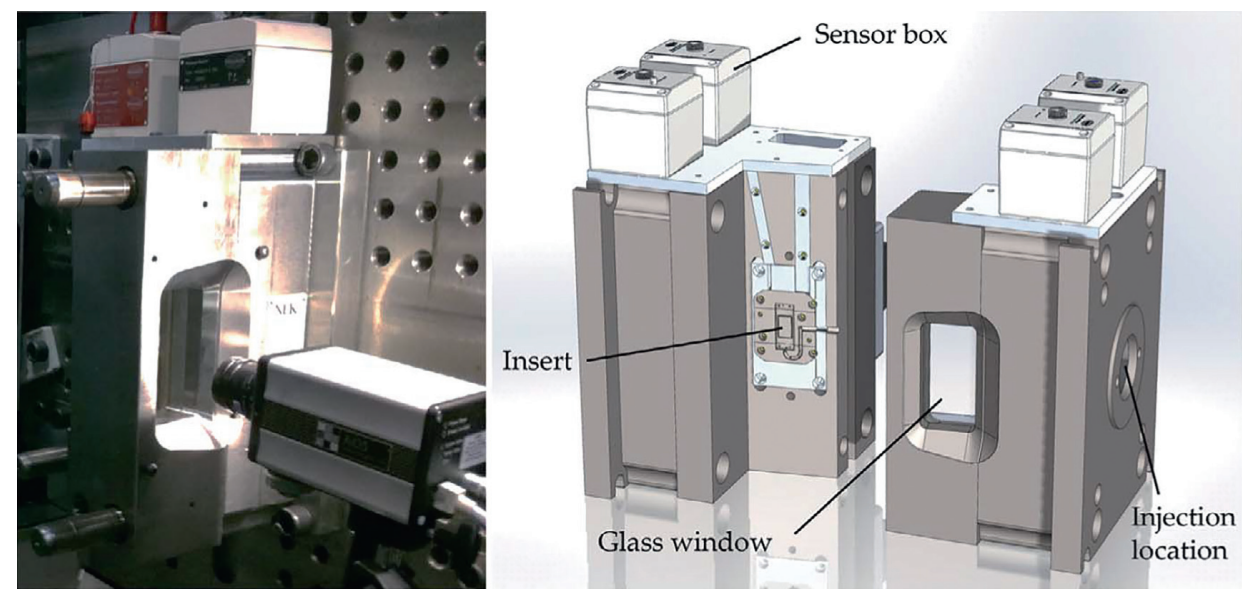

Figure 6: Schematic overview of the visualization mold [57].

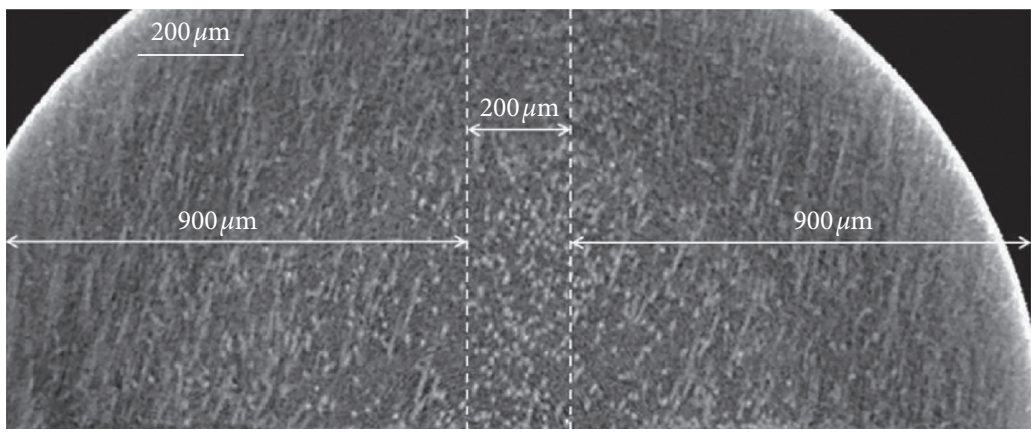

(a)

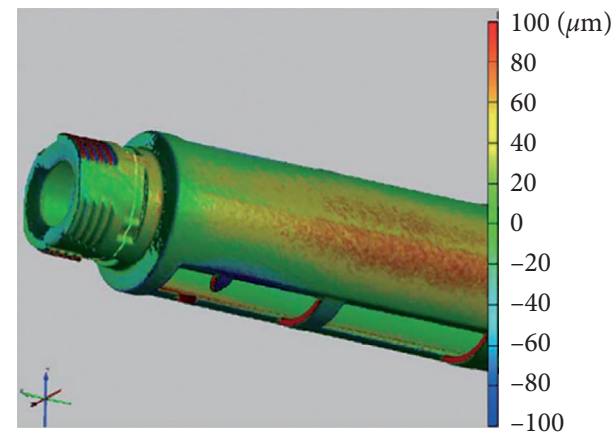

(b)

Figure 7: (a) Fiber orientation of the GF/PA6 specimen shown by the longitudinal section X-ray CT image [64]. (b) Comparison with the CAD model of an injection molded cartridge holder [61].

have done many works and achievements on this particular field [81, 82, 85-87]. By flattening the device (cf. Figure 9(b)), the ability to measure samples with large densities was achieved [83, 88, 89]. Moreover, our research group employed ring magnets to MagLev [90, 91] ensuring better visibility, accessibility, and operability of the samples.

The research by Subramanian and colleagues found that the levitation posture of a sample was correlated with the sample's shape [92]. Hence, Hennek's work explored the possibility of using the MagLev method for quality control of plastic parts [93]. Recently, our research group further analyzed the correlation between the position of the defects and the levitation posture of the sample [94, 95]. This method is further applied in the evaluation of washers [82] and injection molded lens [96] and subtle differences could be detected (cf. Figure 9(c)). Besides, based on its high accuracy, the MagLev method was also studied in separating and recycling different polymers via small differences in density $[84,97,98]$ (cf. Figure 9(d)).

In summary, ultrasound is an outstanding and integrated method for online process sensing of injection molding as it is a nondestructive method that provides rich information. CT scanning can provide abundant product quality features. MagLev is a good emerging method for product defect detection. It has excellent measurement accuracy at a low cost, making it worthy of pursuing.

\section{Optimization of Process Parameters}

The injection molding process involves dozens of process parameters such as injection speed and pressure, packing duration and pressure, mold temperature, and cooling time. The effects of these parameters are coupled to each other, which makes it very difficult to set the process parameters and often relies heavily on the long-term experience of skilled operators.

Many studies have been conducted for the optimization of injection molding processes in order to reduce the time to market and to obtain consistent quality molded parts, and some methods have been put forward. Generally, these optimization methods can be classified into three categories. The first category involves identifying optimal process settings by noniterative analysis based on experimental or simulated results. It also involves analysis based on past experience. The second category establishes relationships between process parameters and product quality through experiments based on the approximate mathematical function obtained by a surrogate model. The third category 


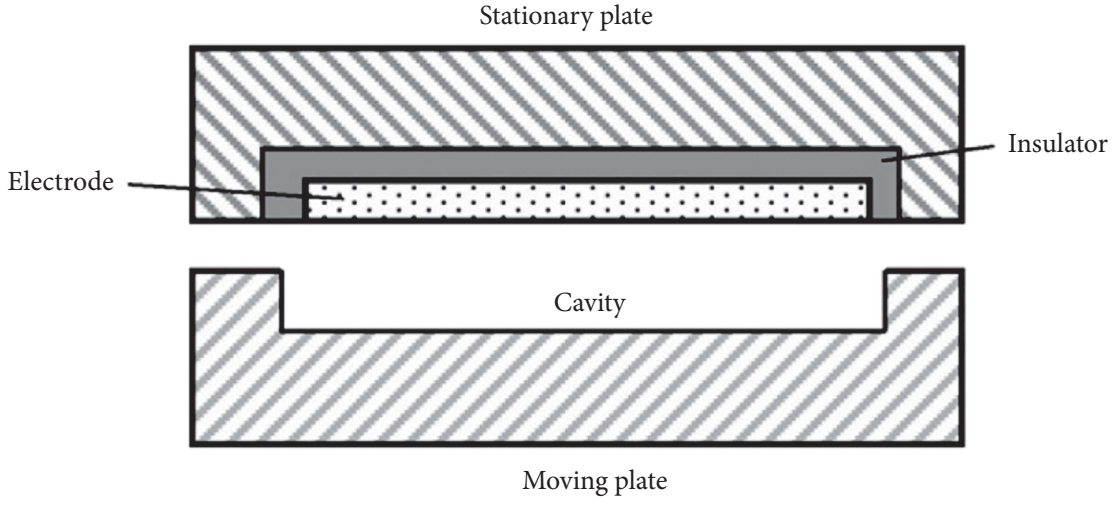

(a)

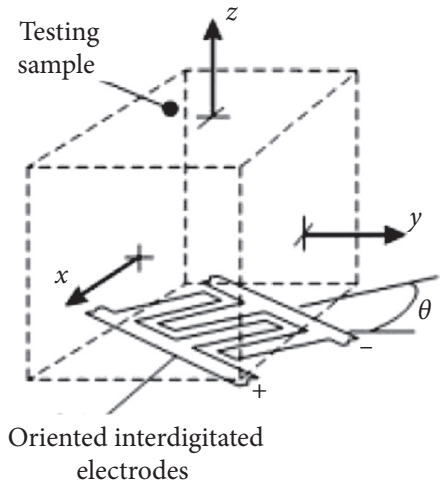

(b)
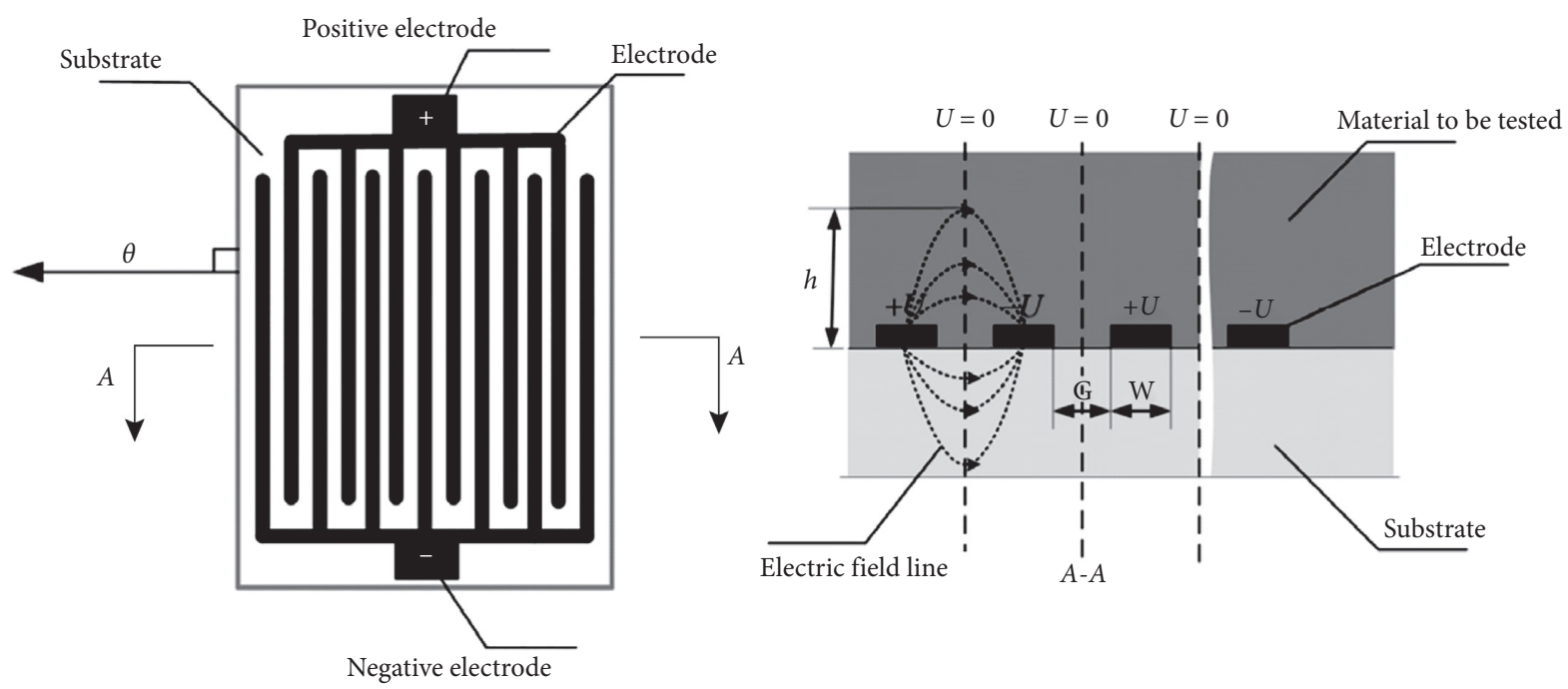

(c)

FIGURE 8: (a) Schematic view of the capacitive transducer installed in the injection mold [68]. (b) Interdigitated electrodes located in the $x y$ plane form an angle, $\theta$, with respect to the $y$-axis [70]. (c) Schematic diagram of interdigitated electrodes.

uses a global search process in a given parameter area, as established by a surrogate model, using intelligent optimization algorithms that follow some rules in nature. These three categories are usually integrated when solving a practical problem and will be introduced in this section.

3.1. Noniterative Optimization Methods. Noniterative methods are generally based on experimental results and practical experiences. They can provide initial process settings or give a direction or route toward optimization. Noniterative optimization methods are easy to implement and require less computation. They have been widely used in research, including the following methods: case-based reasoning (CBR) [3], expert system, fuzzy system [99], and the Taguchi method [100-116].

When optimizing process parameters, implementing a set of real injection molding experiments [111] is a reliable way to gain product quality information under certain parameter settings. However, due to time, expense, and other reasons, a method using simulation analysis $[101-104,107-110,117-120]$ is more likely to be used in research to characterize the impact of various levels of various parameters on the product quality. Some common software packages for simulation include Moldflow, Moldex3D, HsCAE, and ANSYS.

3.1.1. Taguchi Method. The Taguchi method is an effective approach for optimizing the throughput in various manufacturing-related processes. It has been extensively used in the engineering design and analysis of optimal manufacturing parameters $[121,122]$. It provides an optimization framework according to experiments and data analysis. Its concrete steps can be divided into (1) determination of the experimental parameters and their levels, (2) design of experiments, (3) implementation of experiments, and (4) data analysis. By analyzing the quality of injection molded products with different parameters, the influence of the process parameters on product quality can be accessed by means of analysis of variance (ANOVA), range analysis, and analysis of signal-to-noise ratio $(\mathrm{S} / \mathrm{N})$. Finally, relatively optimal parameter settings can be determined.

Applying the Taguchi method, Kuo and Liao [100] and Lin and Hsieh [101] investigated the influence of parameters on the accuracy of lens geometry. Many other 


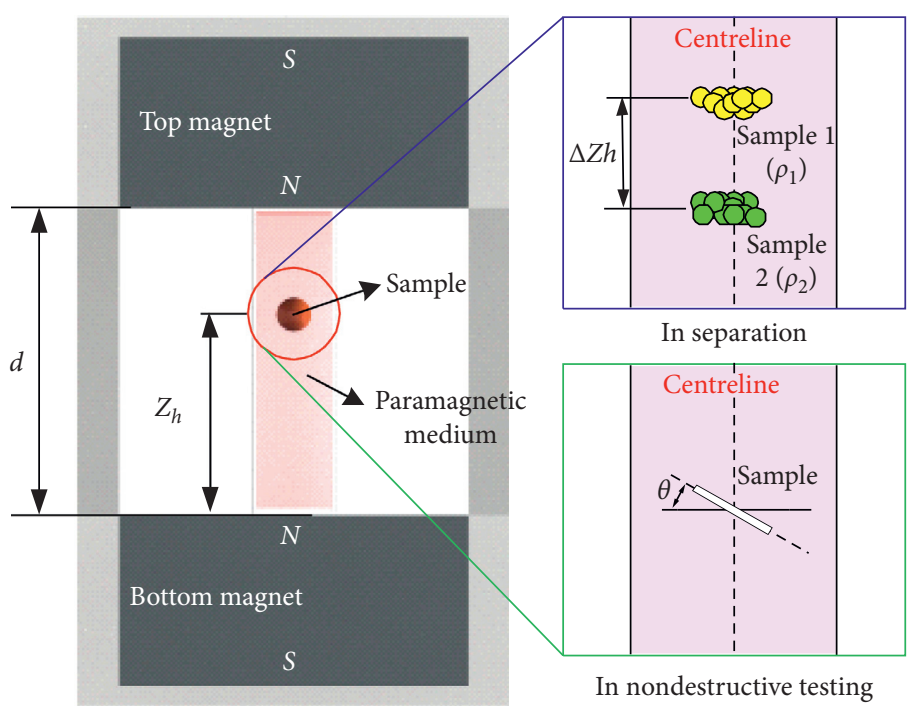

(a)
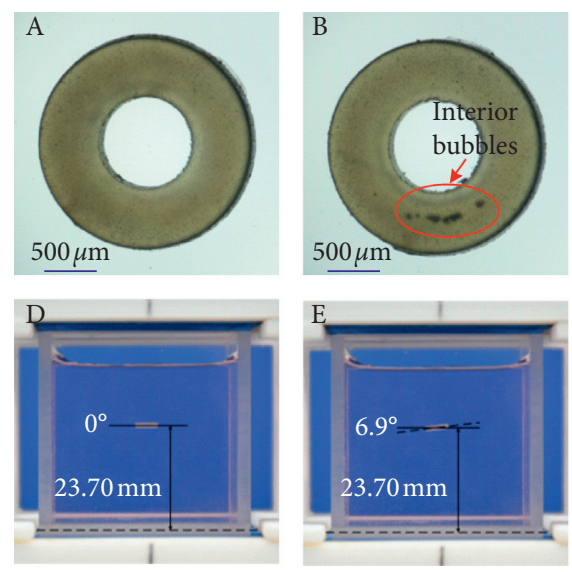

(c)

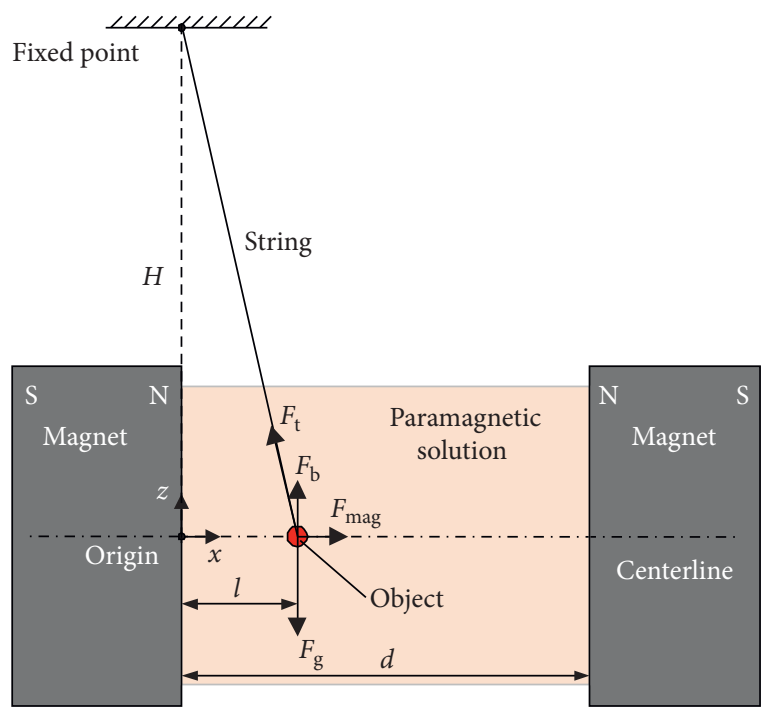

(b)

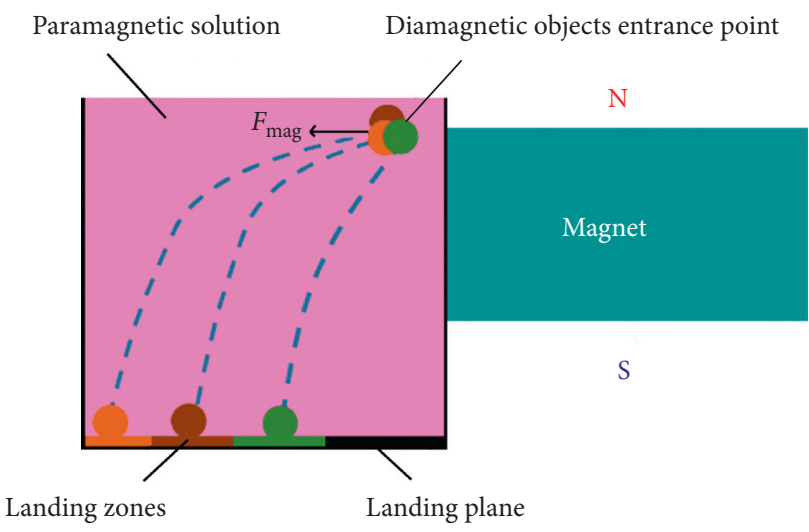

(d)

Figure 9: (a) Schematic view of the magnetic levitation detection device [82]. (b) Horizontal magnetic levitation for enlarging density measurement range [83]. (c) Samples and their levitation posture and position in MagLev device [82]. (d) A novel separation device using the magnetic levitation method [84].

researchers have also applied the Taguchi method to optimize residual stress, volume shrinkage, and warpage properties [102-104]. Xie et al. [106] took four parameters into account and investigated the effect of key injection molding process parameters on the density and strength of a specimen. Wang et al. [108] extended the range of variables investigated to the number of gates, gate size, mold temperature, polymer temperature, fill volume conversion, $\mathrm{V} / \mathrm{P}$ switch over, and cooling time. Analysis of the signalto-noise ratio (S/N) and analysis of variance (ANOVA) were conducted and the best process parameters were found. Using this method, the compression strength increased $12 \%$ compared to the average of the experiment. Sánchez-Sánchez et al. [114] employed the Taguchi method to achieve the optimum level of ultrasonic-assisted injection molding parameters and to maximize the tensile strength of the ultrahigh molecular weight polyethylene (UHMWPE)/graphite composites; the tensile strength was increased by $8.8 \%$.
The foundation of designing an experiment with the Taguchi methodology is the orthogonal array. By using an orthogonal array, a better design on sets of samples can be achieved and results can be obtained by running the simulation code or performing corresponding experiments.

An orthogonal array is a typical design of experiments (DOE) method. Besides the Taguchi method, it is widely applied in other optimization solutions for designing sets of samples. The practical process usually contains multiple influencing factors. The full-factor design includes all possible combinations of all factors and levels and as such it requires a large number of trials that take a lot of time and is too costly to implement. DOE, however, can significantly reduce the number of experiments needed while still revealing the main effects. DOE are almost exclusively used in iterative and noniterative methods. The orthogonal experimental design (OED) used in the Taguchi method is the most extensively used DOE method. In addition, there are many other DOE methods such as CCD, BBD, and LHD. 
Table 1 exhibits the most common DOE methods used in the literature.

3.1.2. Intelligent Methods. Case-based reasoning (CBR) is a procedure that uses an old solution to solve new problems and to evaluate new solutions for further application. CBR is a good method to determine the initial process parameters. The difficulty lies mainly in the description and definition of new problems and finding old solutions to match. The optimization results are strongly dependent on the case library.

Expert systems (ESs) are a subbranch of artificial intelligence that solve problems and give advice using the knowledge of human experts within a specific domain. ESs employ expert-level knowledge to achieve expert performance for the sake of solving specific problems. Their knowledge is both theoretical and practical; that is, the human experts who provide the system's knowledge have generally augmented their own theoretical understanding on the problem domain.

Fuzzy systems are an approximate inference methodology based on the concept of fuzzy set theory. The fuzzy rules and their membership functions compose the system's knowledge base $[3,4]$. The fuzzification procedure converts the input variables into fuzzy values, while the defuzzification procedure transforms fuzzy results into crisp output variables. The fuzzy inference engine uses fuzzy rules during each evaluation cycle.

Expert systems and fuzzy reasoning are methods of modifying process parameters, combined with process parameters and product defects, based on some refined knowledge of the human experience. These methods can guide optimization [132] and optimize some product defects that cannot be quantitatively described, such as flash, flow lines, and pores.

Zhou et al. [4] adopted the idea of case-based reasoning (CBR) to determine the initial process parameters and discussed four case-adaptation strategies. The ideology of fuzzy inference based on expert knowledge and practical experience was utilized for defect correction and process parameter optimization. The fuzzy rules and membership function were discussed. Finally, an integrated intelligent optimization system based on CBR and fuzzy reasoning was constructed. A CBR adaptation strategy was employed to simplify the model into a combination of several basic geometries, and a simplified simulation model was applied to the CBR method to obtain initial parameter settings [5]. Furthermore, based on the previous work, Zhao et al. [3] introduced the empirical model (EM) into the optimization system, combined with the CBR method, to give the initial process parameters, and fuzzy logic algorithm was then combined to optimize the defects, and this system was effectively applied in practical production.

3.2. Surrogate Models. Surrogate models are not an independent method for optimization. They were originally used as a tool for fitting data and can be applied to the optimization process. The optimization results obtained by a
TABLE 1: A brief summary of DOE methods for injection molding optimization.

\begin{tabular}{lc}
\hline Method of DOE & Optimization objective \\
\hline & Warpage \\
& {$[103,104,109,115,116,123]$} \\
Orthogonal experimental & Shrinkage $[103,109,111]$ \\
design (OED) & Mechanical properties \\
& {$[105,106,108]$} \\
& Multiple properties $[102,107]$ \\
Central composite design & Dimensional accuracy [100] \\
(CCD) & Residual stress [101, 103] \\
Box-Behnken design (BBD) & Tensile properties $[124]$ \\
Latin hypercube design & Conversion of RIM [127] \\
(LHD) & Warpage and cycle time [128, 129] \\
& Shrinkage and clamping force [130] \\
\hline
\end{tabular}

noniterative method are often only a local optimal combination of parameters. In order to obtain a global optimal result, some surrogate models are needed to correlate process parameters and objectives because it is expensive and impractical if the techniques involve a time-consuming simulation for each function evaluation. Commonly used surrogate models include the response surface method (RSM), artificial neural network (ANN), support vector regression (SVR), Kriging model, and the Gaussian process. A survey of surrogate models for injection molding optimization in recent years is shown in Table 2. Some surrogate models, such as RSM and ANN, can be utilized in the noniterative method as an experimental data processing method, where a reasonable interval of parameters can be given as a process window. Generally, surrogate models serve as an approximation function for each iteration of the intelligent algorithm, which will be introduced in the next section.

The polynomial models generated by RSM are often referred to as response surface (RS) models in the literature. RS is a model building technique based on the statistical design of experiment (DOEe) and least-square-error fitting methods. When constructing an RSM model, regression analysis is performed. If the user has prior knowledge about the objective problem, the proper model can be chosen. Otherwise, several models need to be constructed from first to third or fourth order, with the best one being selected among the models according to the predicted errors. Heidari et al. [125] constructed an RSM to optimize the shrinkage and warpage of three polylactic acid (PLA)based bone screws. Using this method, they successfully obtained the minimum shrinkage and warpage of the product.

ANNs are widely accepted as a type of technology that offers an alternative way of simulating complex and illdefined problems. They have been used in diverse applications and are particularly useful in system modeling similar to RSM. An ANN is made up of one or more hidden layers placed between the input and output layers. It has a computational structure that consists of a number of highly interconnected processing units called neurons. The neurons sum up weighted inputs and then apply a linear or nonlinear 
TABle 2: A survey of surrogate models for injection molding optimization.

\begin{tabular}{|c|c|}
\hline Surrogate model & Application \\
\hline \multirow{4}{*}{ RSM $[112,124,125,127,133,134]$} & $\begin{array}{l}\text { Shrinkage and } \\
\text { warpage }\end{array}$ \\
\hline & $\begin{array}{c}\text { Conversion of } \\
\text { RIM }\end{array}$ \\
\hline & Tensile properties \\
\hline & Energy efficiency \\
\hline \multirow{4}{*}{$\begin{array}{l}\text { Artificial neural network } \\
{[113,123,128-131,135-139]}\end{array}$} & $\begin{array}{c}\text { Shrinkage and } \\
\text { warpage }\end{array}$ \\
\hline & Cycle time \\
\hline & Clamping force \\
\hline & $\begin{array}{c}\text { Mechanical } \\
\text { properties }\end{array}$ \\
\hline Kriging model [140-142] & Warpage \\
\hline
\end{tabular}

function to the resulting sum in order to determine the output. The ANN learns to approximate the functions through a training process and adjusts their weights and biases until a performance index reaches a preset threshold value. Kitayama et al. $[128,129]$ developed an injection mold with a conformal cooling channel, combined with computer simulation, using a radial basis function network for multiobjective optimization of the injection process. The cycle time improved by $26 \%$, and the warpage improved by $14 \%$ using an optimal combination of process parameters. Jou et al. [112] and Oliaei et al. [113] optimized the injection parameters using response surface methodology and neural network methods, respectively, and a lower product shrinkage was achieved. Also, the Taguchi method was applied and compared with those surrogate models, and the results were in good agreement.

There are many other surrogate models that are utilized for constructing approximation functions based on experiments or simulation such as support vector machines (SVM) [143] and the Kriging model. They have similar roles in optimization and will not be specifically introduced here. These surrogate models serve an objective function for the characterization of the iteration results when conducting iterate optimization strategies, thus making the evaluation of iteration results less time-consuming $[123,130,131$, $133,135,136,141,144,145]$.

3.3. Iterative Optimization Methods. As mentioned above, a simple optimization algorithm based on experiments and data analysis is unlikely to give a global optimal solution. In order to obtain better optimization results, iterative optimization algorithms are often utilized to obtain a convergent global optimal combination of parameters. Iterative optimization approaches can be classified into deterministic and stochastic approaches according to the methods of improving the optimal point within each iteration [132]. Stochastic approaches have been mostly employed for injection molding process parameter optimization and are generally referred to as intelligent optimization algorithms. These algorithms include the genetic algorithm (GA) [123, 133, 134, 146-155], particle swarm optimization (PSO)
[99, 131, 136, 147, 151-153, 156, 157], simulated annealing, and hill climbing. These algorithms start with random variables and iterate for the next variables according to their own iterative principles until the optimal points are found. Iterative directions are determined similar to the evolution of natural phenomena. Surrogate models are applied to characterize the quality of the products under the parameters settings after every iteration. Global optimal parameter settings are expected to be found after several runs or iterations, and thus, they become a feasible approach for the optimization of injection molding parameters. However, the probability of finding the global optimal solution decreases as the problem size increases.

Genetic algorithms are search algorithms designed to mimic the principles of biological evolution in a natural genetic system. GAs can be used to solve difficult problems in terms of objective functions that possess "bad" properties, such as those that are multimodal, discontinuous, and nondifferentiable. These algorithms maintain and manipulate a population of solutions and implement their search for better solutions based on a "survival of the fittest" strategy. This provides an implicit as well as explicit parallelism that allows for the exploitation of several promising areas for a given solution space at the same time. Applying the genetic algorithm combined with an RSM model, Park and Nguyen [133] solved the multiobjective optimization problem of energy consumption and product quality. Li et al. [123] minimized warpage for fiber-reinforced composite injection molding by combining a GA with a BP neural network. Zhao et al. [146] employed the improved effective global optimization (IEGO) algorithm to approximate the nonlinear correlation between process parameters and quality indicators of a final product, and then the nondominated sorting genetic algorithm II (NSGA-II) was developed to find the combination of process parameters for the smallest warpage and volume shrinkage of plastic products.

The particle swarm optimization methods were first inspired by the biological and social behavior of bird flocks and fish schools [158]. This behavior was collectively referred to as swarming. When a swarm looks for food, its individuals will spread out in the environment and move around independently. Each individual has a degree of freedom or randomness in its movements, which enables it to find food. Sooner or later, one of them will find something digestible and, as being social, will announce this to its neighbors [159]. In PSO, the potential solutions, called particles, are analogous to birds or fish. These particles fly according to their own flying experiences and their companions' flying experiences.

Applying PSO, Kramar and Cica [99] maximized the tensile strength of molded products. Zhang et al. [131] carried out a multiobjective optimization of injection molding process parameters of diesel engine oil cooler covers based on the ellipsoid basis function neural network. $\mathrm{Xu}$ et al. [136] developed a back-propagation neural network model to reflect the complex nonlinear correlation between process parameters and product mechanical properties. They found that the particle swarm optimization algorithm significantly improved the mechanical properties-and hence the performance-of the product. 
There are many other evolutionary algorithms, such as simulated annealing algorithms and ant colony algorithms, which share many similarities with other GA and PSO models. They both initialize a population in a similar manner and search for an optimal solution by updating generations. They have been successfully applied in many research and industry applications.

Ideal injection molding process optimization results always come from a combination of using a variety of methods. This is summarized in Figure 10. Generally, it starts with a noniterative method like CBR to give an initial process setting and then the design of experiments (DOEe) technique is used to provide sets of samples. After performing the experiments and analyzing the influence of different parameters, a local optimal combination of parameters can be given like a process window. Furthermore, surrogate models can be employed to correlate process parameters and objectives. Hence, one can optimize the process parameters and obtain an optimized product quality with the application of intelligent iterative algorithms such as genetic algorithms and particle swarm optimization models.

For example, the GA approach was combined with BPNN [149], RSM [134, 150], and the Kriging model [148] as surrogate models. The optimal combination of process parameters was obtained and became stable. Also, the PSO algorithm was applied with BPNN to optimize the flash and volume shrinkage of injection molded parts [157]. Moreover, a GA/PSO hybrid approach was developed to serve as an iterative method $[147,152,153]$ and with the assistance of BPNN or RSM the warpage was reduced by $38.6 \%$.

The model-free optimization (MFO) algorithm is also an effective method. Johnston et al. [160] and Yang et al. [161] developed an online, model-free process optimization method and obtained ideal convergent results. A systematic approach that combined digital image processing (DIP) and model-free optimization (MFO) was proposed to solve optimization problems [161]. MFO uses measurements like DIP as feedback to determine the optimal settings, which is a typical online intelligent optimization approach.

\section{Process Control}

The control target of the machine includes the injection speed, shot size, screw rotation speed, cylinder pressure, injection pressure, packing pressure, packing pressure, barrel temperature, and coolant temperature. These quantifiable and easily measured variables are the most common control variables in modern industrial injection molding. The precise closed-loop control of these variables ensures high repeatability of the injection molded process and the resultant product.

The injection molding process is a typical cyclic batch process. Obviously, the control algorithm for the batch process is different from the continuous process. Due to the nonlinear and time-varying complex dynamic characteristics of the batch process, it is much more difficult than a continuous process. Therefore, the development of injection molding process control has gradually transferred from the traditional continuous-control strategy to control strategies

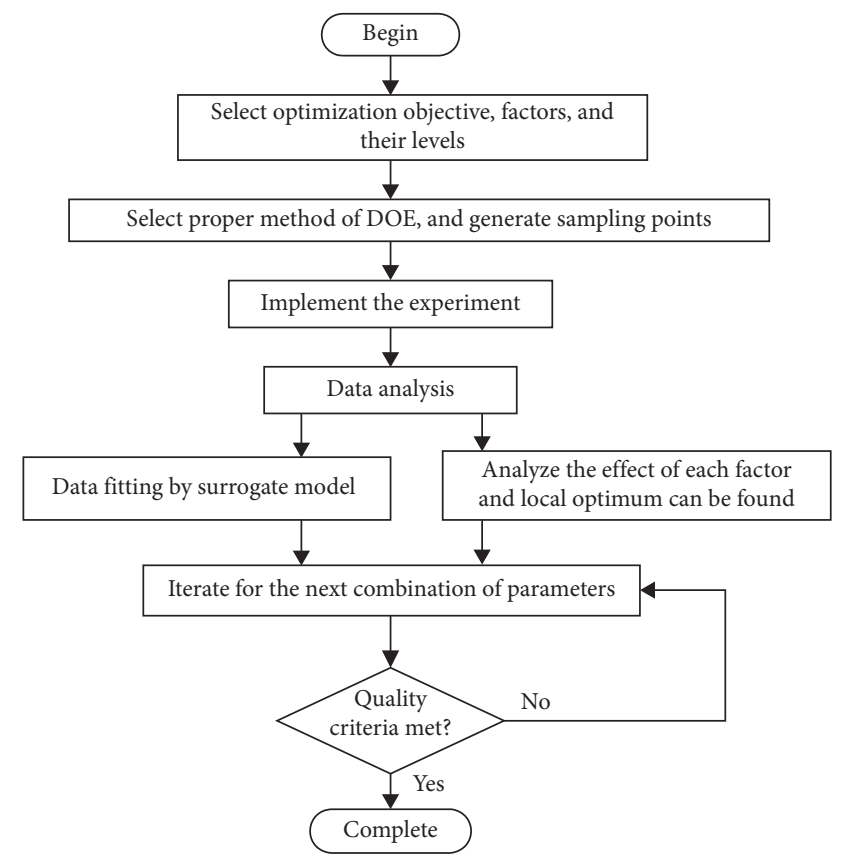

FIgURE 10: A flowchart of the overall optimization of injection molding parameters.

that focus on batch-direction characteristics. The research group of Gao $\mathrm{F}$ has made great advances in this field $[144,162-175]$. This section will introduce the application of two typical strategies in injection molding-traditional feedback control and iterative learning control-and summarize and analyze them. Finally, the latest relevant studies will be introduced.

\subsection{Feedback Control}

4.1.1. Proportional-Integral-Derivative (PID) Controller. The PID controller is the most standard feedback control algorithm and measures the controlled variable, calculates the error between the output and set point, and generates the controller output based on the proportional, the integral, and the derivative of the errors. In brief, a PID controller makes use of the error to adjust the output to obtain the set variables. Researchers have achieved control of mold temperature [176], servohydraulic systems [177], and the stability of product quality [143] using PID controllers.

However, traditional PID control does not work well for the injection molding process due to its batch operation nature and the nonlinear and time-varying characteristics of the process. Adaptive control is a good alternative for this kind of control. Its parameters are adapted in a certain way to conform to the nonlinear or time-varying process dynamics and provide good control performance. Yang and Gao proposed a self-tuning adaptive controller [162] for injection velocity control, and robustness and tracking performance were improved.

4.1.2. Model Predictive Control. Model predictive control (MPC) can obtain the control signal by optimizing future 
behavior through minimizing a cost function and making explicit use of a prediction model. It predicts the process output of future time over a certain period, called the prediction horizon. MPC calculates a set of future input for certain steps by minimizing a cost function, called the control horizon, so that the predicted output reaches the set point in an optimal manner. It is suitable for batch processes since the reference trajectories of the process settings are known before the cycle starts. This controller has been successfully applied in the injection molding process to control the screw speed and hydraulic back pressure $[178,179]$, coolant flow, coolant temperature [180], and cavity pressure $[181,182]$. The group of Zhang et al. $[166,167,170,173,183]$ designed fault-tolerant control through a predictive functional control framework for a batch process with unknown disturbances and partial actuator failures to achieve the desired closed-loop response.

Based on the fuzzy logic and neural network systems, establishing a precise model in process control can be avoided. If constructed from human knowledge in the form of fuzzy IF-THEN rules, it can easily perform multi-input, single-output, nonlinear mapping from a multidimensional vector to a scalar. This method has been used to control the injection speed and repeatability $[184,185]$. Kanagalakshmi et al. [186] developed a multimodel control strategy that comprehensively included a variety of approaches, such as PID, fuzzy, and adaptive neurofuzzy inference system (ANFIS) control. The weighted average of these three strategies was utilized to control the barrel plasticizing temperature.

4.2. Learning Control. Injection molding is a batch process with a repetitive property. It is different from continuous process control where past control information can be used to improve current and future cycles. This kind of cycle-tocycle improvement is similar to the human learning process; therefore, it is called learning control.

4.2.1. Conventional Iterative Learning Control. The batch process is usually described by two dimensions-the time dimension and the cycle dimension (batch dimension). The repetitive nature of the batch dimension can be used to guide the control output of the system. Generally, there are two ways to improve the learning control performance along the cycle direction: controller parameter learning and iterative learning control. Controller parameter learning adjusts and updates the controller parameters from cycle to cycle. Control signal learning control, also called iterative learning control (ILC), adjusts the controller output directly. The ILC method has been widely used in injection molding to achieve stable tracking of the time and batch sequence of the set point trajectory so as to improve process accuracy and repeatability $[164,169,187,188]$.

4.2.2. Two-Dimensional (2D) Control. Conventional ILC is only cycle-wise feedback control, with cycle-wise integral action that ensures performance improvement along the cycle direction. Two-dimensional feedback control is the strategy to ensure performance improvement along both time and cycle directions. The integral action along these two directions forms a 2D integrator cascade for eliminating the control error within and along the time and cycle directions.

The research on this control approach was also mainly studied by Gao's group. They proposed a robust 2D feedback control combined with an iterative learning control (FILC) method for batch processes [165, 171, 172]. They further proposed iterative learning fault-tolerant control (ILFTC) for uncertain disturbances and fault conditions [168]. Then, a novel $2 \mathrm{D}$ predictive functional iterative learning control (ILC) scheme $[175,189]$ was developed, thus introducing a new model formulation and error compensation approach. They also proposed some hybrid methods that combined conventional MPC with ILC to yield two-dimensional time model predictive control [174], combined with ILC and predictive function control (PFC) [163].

Due to the nonlinear and time-varying characteristics of the injection molding process, conventional feedback control strategies are not very effective for batch process control. This is because the information in the batch direction is an important guidance for control strategies. The iterative learning control method is the earliest effective strategy. After that, by introducing the feedback control of the time dimension, one can achieve faster convergence and better tracking performance. Using control strategies involves a lot of expertise in control discipline. Readers who are interested can consult more detailed references $[2,190]$ in this field.

4.2.3. Reinforcement Learning Control. Reinforcement learning $(\mathrm{RL})$ is the learning from the environment to behavior mapping, which aims at allowing the agent to learn how to behave in an environment through the interaction with the environment. Intelligent system through interaction with the environment achieves the maximum reward signal. Recently, with the combination of artificial neural networks (ANNs), RL has attracted more attention in solving practical control problems [191]. Reinforcement learning control (RLC) can effectively handle nonlinear and highly uncertain systems. It is a powerful algorithm for solving optimal control problems.

Ruan et al. [192] first proposed applying RLC to the field of injection molding control. They proposed a hybrid method that combined RLC with ILC to solve the motion control problem in injection molding. RLC is ideal for optimal control, but it is not suitable for precise tracking control. Therefore, by combining with other tracking control algorithms, such as iterative learning control, it can effectively solve the motion control problems in injection molding.

\section{Conclusions and Prospects}

This review introduces methods and strategies on the sensing, optimization, and control of intelligent injection molding and summarizes recent studies in these three areas. As for process sensing, conventional methods like pressure 
and temperature sensors are still indispensable, while emerging methods like ultrasound can obtain other important physical variables to enrich the information extracted from the process. In terms of parameter optimization, intelligent algorithms combined with surrogate models have gradually become the widely used optimization method and have delivered increasingly excellent results. In machine control, feedback control and learning control are currently the most effective control algorithms for typical batch processes. At present, these three areas have achieved considerable development. Furthermore, it can be concluded that the main research trend in the future lies in the integration of these three areas and in achieving reliable and real-time control of product quality in a more efficient and intelligent manner. However, there are still some problems that need to be further studied in order to achieve intelligent injection molding, including the following aspects.

\subsection{Perception and Reconstruction of Multiple Physical Fields.} There are many methods for detecting or diagnosing the physical parameters of the molding process. However, it can be found in the literature that the methods can only detect physical variables at some finite points. Some papers have suggested a data-fitting method to obtain the distribution of certain physical fields in the cavity. There is also an ultrasound "tomography scan" to construct the temperature field. But such methods are indirectly calculated and there are considerable errors. How to develop advanced sensing technology in the future and realize the perception of the physical field will continue to attract much interest, such as using a pressure detection film to detect the pressure distribution of the entire domain. In addition, it is still quite difficult to detect some microscopic physical variables online. A number of investigations applying ultrasound and dielectric methods to detect microphysical variables have emerged, but they are still in the early stages. Moreover, it is worth looking forward to the advancement in physics and modeling; it could directly enhance the observability of many physical variables in what are otherwise confounded states (e.g., barrel temperature and melt pressure). In this field, there are many scientific and engineering problems worth exploring.

5.2. Autonomous Learning Driven by Big Data. With the development of information technology, more and more data can be collected in the current industrial production process, including the process parameters and product quality of each batch. If autonomous learning based on big data analysis can be realized, higher efficiency in the optimization of process parameters can be achieved. It is without a doubt though that this process contains many difficulties, such as data standards and protocols, the accurate acquisition of data samples, and the integration of various complicated methods. It is believed that future technological breakthroughs in this area will bring fruition to industrial integration and production.

5.3. Definition of Product Quality Characteristics. It is well known that many types of defects in injection molded parts cannot be accurately described under certain circumstances. Some process optimization methods already have the capability of giving a better combination of process parameters, but these methods are often offline. To realize the combination of online detection and process optimization, a definition of quality characteristics of injection molded parts is very important. The approach may be to estimate their physical valuables per area. At present, the online detection mode for product weight, density, warpage, etc., is insufficient, and a direct quality feedback control system has yet to be developed. Hopmann and Heinisch [185] have made a great attempt in this direction even though they characterized the viscosity of the melt rather than the part quality. In addition, there are some product defects such as flow marks and bubbles that cannot be characterized quantitatively, thus rendering quantitative optimization methods inadequate. Therefore, how to properly characterize defects and further promote them will be a new trend in future optimization studies.

\subsection{Model Identification Based on the Learning Method.} For a batch process like injection molding, the development of feedback control and learning control reduces the dependence of the algorithm on the model. However, for model-based control algorithms, an accurate model has a crucial influence on the control result. And a good model can still accelerate the convergence of the algorithm and improve the tracking performance. During the injection molding process, the batch-direction data can be considered as a basis for system modeling and the characteristics of the batch can be further exploited. In addition, owing to changes in molds and materials, previous algorithms cannot necessarily be continued, which also puts forward new requirements for the modeling of the process.

\section{Conflicts of Interest}

The authors declared no potential conflicts of interest with respect to the research, authorship, and/or publication of this article.

\section{Acknowledgments}

The authors would like to acknowledge the financial support of the National Natural Science Foundation Council of China (nos. 51875519, 51635006, and 51821093), the Zhejiang Provincial Natural Science Foundation of China (no. LZ18E050002), and the Key Research and Development Plan of Zhejiang Province (no. 2020C01113).

\section{References}

[1] State \& Congressional Data, 2019, http://www.plasticsindustry. org/advocacy/state-congressional-data.

[2] H. Zhou, Computer Modeling for Injection Molding: Simulation, Optimization, and Control, John Wiley \& Sons, Hoboken, NJ, USA, 2013.

[3] N. Zhao, Z. Zhao, S. Liao, and S.-B. Cui, "Probabilistic model combination for support vector machine using positive- 
definite kernel-based regularization path," Advances in Intelligent and Soft Computing, vol. 12, no. 3, pp. 201-206, 2011.

[4] H. Zhou, P. Zhao, and W. Feng, "An integrated intelligent system for injection molding process determination," $A d$ vances in Polymer Technology, vol. 26, no. 3, pp. 191-205, 2007.

[5] D. Li, H. Zhou, P. Zhao, and Y. Li, "A real-time process optimization system for injection molding," Polymer Engineering \& Science, vol. 49, no. 10, pp. 2031-2040, 2009.

[6] J. Zhou, P. Li, Y. Zhou, B. Wang, J. Zang, and L. Meng, "Toward new-generation intelligent manufacturing," Engineering, vol. 4, no. 1, pp. 11-20, 2018.

[7] H. Zhang, L. Ren, Y. Gao, and B. Jin, "A comprehensive study of energy conservation in electric-hydraulic injectionmolding equipment," Energies, vol. 10, no. 11, p. 1768, 2017.

[8] Z. Chen and L.-S. Turng, "A review of current developments in process and quality control for injection molding," Advances in Polymer Technology, vol. 24, no. 3, pp. 165-182, 2005.

[9] P. Zhao, H. Zhou, Y. He, K. Cai, and J. Fu, "A nondestructive online method for monitoring the injection molding process by collecting and analyzing machine running data," The International Journal of Advanced Manufacturing Technology, vol. 72, no. 5-8, pp. 765-777, 2014.

[10] J.-S. Gim, J.-S. Tae, J.-H. Jeon, J.-H. Choi, and B.-O. Rhee, "Detection method of filling imbalance in a multi-cavity mold for small lens," International Journal of Precision Engineering and Manufacturing, vol. 16, no. 3, pp. 531-535, 2015.

[11] X. Zhou, Y. Zhang, T. Mao, and H. Zhou, "Monitoring and dynamic control of quality stability for injection molding process," Journal of Materials Processing Technology, vol. 249, pp. 358-366, 2017.

[12] Q. Wang, M. Zhen, Z. Wu, Y. Cai, T. Kuo-Ming, and L. JunKai, "Effect of process parameters on cavity pressure in injection molding," AIP Conference Proceedings, vol. 1820, no. 1, Article ID 050005, 2017.

[13] H. Hassan, "An experimental work on the effect of injection molding parameters on the cavity pressure and product weight," The International Journal of Advanced Manufacturing Technology, vol. 67, no. 1-4, pp. 675-686, 2013.

[14] X. Zhou, Y. Zhang, T. Mao, Y. Ruan, H. Gao, and H. Zhou, "Feature extraction and physical interpretation of melt pressure during injection molding process," Journal of Materials Processing Technology, vol. 261, pp. 50-60, 2018.

[15] H. S. Park, D. X. Phuong, and S. Kumar, "AI based injection molding process for consistent product quality," Procedia Manufacturing, vol. 28, pp. 102-106, 2019.

[16] H. Zamani, S. Azmoudeh, and K. Shelesh-Nezhad, "Warpage characterization of thin and centrally-gated injection molded part by applying cavity pressure measurement," in Advanced Research in Material Science and Mechanical Engineering, Pts 1 and 2, H. Rui, Ed., pp. 1099-1103, Trans Tech Pubilcations, Beijing, China, 2014.

[17] T. Mao, Y. Zhang, Y. Ruan, H. Gao, H. Zhou, and D. Li, "Feature learning and process monitoring of injection molding using convolution-deconvolution auto encoders," Computers \& Chemical Engineering, vol. 118, pp. 77-90, 2018.

[18] M. Heinle and D. Drummer, "Measuring mechanical stresses on inserts during injection molding," Advances in Mechanical Engineering, vol. 7, no. 5, p. 6, 2015.

[19] K. M. Tsai and J. K. Lan, "Correlation between runner pressure and cavity pressure within injection mold," The
International Journal of Advanced Manufacturing Technology, vol. 79, no. 1-4, pp. 273-284, 2015.

[20] W. S. Guan and H. X. Huang, "A proposed technique to acquire cavity pressure using a surface strain sensor during injection-compression molding," Journal of Manufacturing Science and Engineering, vol. 135, no. 2, p. 6, 2013.

[21] Y. Zhang, T. Mao, Z. Huang, H. Gao, and D. Li, "A statistical quality monitoring method for plastic injection molding using machine built-in sensors," The International Journal of Advanced Manufacturing Technology, vol. 85, no. 9-12, pp. 2483-2494, 2016.

[22] G. Wang, G. Zhao, and X. Wang, "Development and evaluation of a new rapid mold heating and cooling method for rapid heat cycle molding," International Journal of Heat and Mass Transfer, vol. 78, pp. 99-111, 2014.

[23] F. De Santis and R. Pantani, "Development of a rapid surface temperature variation system and application to micro-injection molding," Journal of Materials Processing Technology, vol. 237, pp. 1-11, 2016.

[24] G.-L. Wang, G.-Q. Zhao, and X.-X. Wang, "Heating/cooling channels design for an automotive interior part and its evaluation in rapid heat cycle molding," Materials \& Design, vol. 59, pp. 310-322, 2014.

[25] G. Wang, Y. Hui, L. Zhang, and G. Zhao, "Research on temperature and pressure responses in the rapid mold heating and cooling method based on annular cooling channels and electric heating," International Journal of Heat and Mass Transfer, vol. 116, pp. 1192-1203, 2018.

[26] L. Crema, M. Sorgato, and G. Lucchetta, "Thermal optimization of deterministic porous mold inserts for rapid heat cycle molding," International Journal of Heat and Mass Transfer, vol. 109, pp. 462-469, 2017.

[27] S. Liparoti, A. Sorrentino, and G. Titomanlio, "Temperature and pressure evolution in fast heat cycle injection molding," Materials and Manufacturing Processes, vol. 34, no. 4, pp. 422-430, 2019.

[28] S. P. Johnston, G. A. Mendible, R. X. Gao, and D. O. Kazmer, "Estimation of bulk melt-temperature from in-mold thermal sensors for injection molding, Part A: method," International Polymer Processing, vol. 30, no. 4, pp. 460-466, 2015.

[29] B. Yang, L. Hu, G.-J. Li et al., "An evaluation of the melt crystallisation behaviour of injection-moulded high-density polyethylene (HDPE) based on a solidification kinetics analysis," Plastics, Rubber and Composites, vol. 46, no. 5, pp. 200-211, 2017.

[30] R. X. Gao, X. Tang, G. Gordon, and D. O. Kazmer, "Online product quality monitoring through in-process measurement," CIRP Annals, vol. 63, no. 1, pp. 493-496, 2014.

[31] G. Gordon, D. O. Kazmer, X. Y. Tang, Z. Y. Fan, and R. X. Gao, "Quality control using a multivariate injection molding sensor," The International Journal of Advanced Manufacturing Technology, vol. 78, no. 9-12, pp. 1381-1391, 2015.

[32] X. Mendibil, I. Llanos, H. Urreta, and I. Quintana, "In process quality control on micro-injection moulding: the role of sensor location," The International Journal of Advanced Manufacturing Technology, vol. 89, no. 9-12, pp. 3429-3438, 2017.

[33] H. Wang, B. Cao, C. K. Jen, K. T. Nguyen, and M. Viens, "On-line ultrasonic monitoring of the injection molding process," Polymer Engineering \& Science, vol. 37, no. 2, pp. 363-376, 1997.

[34] B. He, Y. Yang, H. Zou, Q. Zhang, and Q. Fu, "Fast determination of phase inversion in polymer blends using 
ultrasonic technique," Polymer, vol. 46, no. 18, pp. 76247631, 2005.

[35] B. He, X. Yuan, H. Yang et al., "Ultrasonic measurement of orientation in HDPE/iPP blends obtained by dynamic packing injection molding," Polymer, vol. 47, no. 7, pp. 2448-2454, 2006.

[36] F. Lionetto and A. Maffezzoli, "Polymer characterization by ultrasonic wave propagation," Advances in Polymer Technology, vol. 27, no. 2, pp. 63-73, 2008.

[37] Y. Zhao, X. M. L. Lin, and M. K. Lei, "Simultaneous determination of the coating thickness and its longitudinal velocity by ultrasonic nondestructive method," NDT \& $E$ International, vol. 43, no. 7, pp. 579-585, 2010.

[38] R. Raisutis, R. Kazys, and L. Mazeika, "Application of the ultrasonic pulse-echo technique for quality control of the multi-layered plastic materials," NDT E International, vol. 41, pp. 300-311, 2008.

[39] W. Michaeli and C. Starke, "Ultrasonic investigations of the thermoplastics injection moulding process," Polymer Testing, vol. 24, no. 2, pp. 205-209, 2005.

[40] M. Aigner, B. Praher, C. Kneidinger, J. Miethlinger, and G. Steinbichler, "Verifying the melting behavior in singlescrew plasticization units using a novel simulation model and experimental method," International Polymer Processing, vol. 29, no. 5, pp. 624-634, 2014.

[41] B. Praher and G. Steinbichler, "Ultrasound-based measurement of liquid-layer thickness: a novel time-domain approach," Mechanical Systems and Signal Processing, vol. 82, pp. 166-177, 2017.

[42] B. Praher, K. Straka, and G. Steinbichler, "An ultrasoundbased system for temperature distribution measurements in injection moulding: system design, simulations and off-line test measurements in water," Measurement Science And Technology, vol. 24, no. 8, Article ID 084004, 2013.

[43] B. Praher, K. Straka, J. Usanovic, and G. Steinbichler, "Ultrasound based monitoring of the injection moulding process-methods, applications and limitations," AIP Conference Proceedings, vol. 1593, no. 1, pp. 159-162, 2014.

[44] L. Zhao, Y. Lai, C. Pei, C.-K. Jen, and K.-D. Wu, "Real-time diagnosing polymer processing in injection molding using ultrasound," Journal of Applied Polymer Science, vol. 126, no. 6, pp. 2059-2066, 2012.

[45] Y. Ono, B. R. Whiteside, E. C. Brown et al., "Real-time process monitoring of micromoulding using integrated ultrasonic sensors," Transactions of the Institute of Measurement and Control, vol. 29, no. 5, pp. 383-401, 2007.

[46] C.-C. Cheng, Y. Ono, and C.-K. Jen, "Real-time diagnosis of co-injection molding using ultrasound," Polymer Engineering \& Science, vol. 47, no. 9, pp. 1491-1500, 2007.

[47] L. Mulvaney-Johnson, C. C. Cheng, Y. Ono, E. C. Brown, C. K. Jen, and P. D. Coates, "Real time diagnostics of gas/ water assisted injection moulding using integrated ultrasonic sensors," Plastics, Rubber and Composites, vol. 36, no. 3, pp. 111-121, 2007.

[48] Y. L. Wu, C. H. Yang, C. C. Cheng, and M. Kobayashi, "Novel real-time diagnostic of injection molding process at nozzle by high-temperature ultrasonic transducer," in Proceedings of the 2015 Ieee International Ultrasonics Symposium, October 2015.

[49] Y.-L. Wu, C.-C. Cheng, M. Kobayashi, and C.-H. Yang, "Novel design of extension nozzle and its application on realtime injection molding process diagnosed by ultrasound," Sensors and Actuators A: Physical, vol. 263, pp. 430-438, 2017.
[50] P. Zhao, Y. Zhao, H. Kharbas et al., "In-situ ultrasonic characterization of microcellular injection molding," Journal of Materials Processing Technology, vol. 270, pp. 254-264, 2019.

[51] P. Zhao, Y. Peng, W. Yang, J. Fu, and L.-S. Turng, "Crystallization measurements via ultrasonic velocity: study of poly(lactic acid) parts," Journal of Polymer Science Part B: Polymer Physics, vol. 53, no. 10, pp. 700-708, 2015.

[52] P. Zhao, S. Wang, J. Ying, and J. Fu, "Non-destructive measurement of cavity pressure during injection molding process based on ultrasonic technology and Gaussian process," Polymer Testing, vol. 32, no. 8, pp. 1436-1444, 2013.

[53] Y. Zhao, P. Zhao, J. Zhang, J. Huang, N. Xia, and J. Fu, "Online measurement of clamping force for injection molding machine using ultrasonic technology," Ultrasonics, vol. 91, pp. 170-179, 2019.

[54] P. Zhao, Y. Zhao, J. Zhang, J. Huang, N. Xia, and J. Fu, "Ultrasonic measurement of clamping force for injection molding machine," Journal of Polymer Engineering, vol. 39, no. 4, pp. 388-396, 2019.

[55] J. Zhang, P. Zhao, Y. Zhao, J. Huang, N. Xia, and J. Fu, “Online measurement of cavity pressure during injection molding via ultrasonic investigation of tie bar," Sensors and Actuators A: Physical, vol. 285, pp. 118-126, 2019.

[56] P. Guerrier, G. Tosello, K. K. Nielsen, and J. H. Hattel, "Three-dimensional numerical modeling of an induction heated injection molding tool with flow visualization," The International Journal of Advanced Manufacturing Technology, vol. 85, no. 1-4, pp. 643-660, 2016.

[57] P. Guerrier, G. Tosello, and J. H. Hattel, "Flow visualization and simulation of the filling process during injection molding," Cirp Journal of Manufacturing Science and Technology, vol. 16, pp. 12-20, 2017.

[58] W.-R. Jong, S.-S. Hwang, C.-C. Wu, C.-H. Kao, Y.-M. Huang, and M.-C. Tsai, "Using a visualization mold to discuss the influence of gas counter pressure and mold temperature on the fountain flow effect," International Polymer Processing, vol. 33, no. 2, pp. 255-267, 2018.

[59] K.-Y. Jiang, Z. Ji, H. Li, M.-J. Wang, and T.-M. Yu, "Polymer flow behavior analysis based on physical visualization technology for ultrasonic vibration-assisted injection molding," International Polymer Processing, vol. 32, no. 3, pp. 290-297, 2017.

[60] K.-Y. Jiang, Y. Zhang, L. Yang, and Y. Lu, "Study on influence of Co-injection molding process on self-reinforcing characteristics of self-reinforced polypropylene composite via visualization," International Polymer Processing, vol. 34, no. 4, pp. 408-415, 2019.

[61] L. De Chiffre, S. Carmignato, J.-P. Kruth, R. Schmitt, and A. Weckenmann, "Industrial applications of computed tomography," CIRP Annals, vol. 63, no. 2, pp. 655-677, 2014.

[62] A. Awal, M. Rana, and M. Sain, "Thermorheological and mechanical properties of cellulose reinforced PLA biocomposites," Mechanics Of Materials, vol. 80, pp. 87-95, 2015.

[63] D. Masato, J. Rathore, M. Sorgato, S. Carmignato, and G. Lucchetta, "Analysis of the shrinkage of injection-molded fiber-reinforced thin-wall parts," Materials \& Design, vol. 132, pp. 496-504, 2017.

[64] T. B. Nguyen Thi, M. Morioka, A. Yokoyama, S. Hamanaka, K. Yamashita, and C. Nonomura, "Measurement of fiber orientation distribution in injection-molded short-glass-fiber composites using X-ray computed tomography," Journal of Materials Processing Technology, vol. 219, pp. 1-9, 2015. 
[65] J. P. Kruth, M. Bartscher, S. Carmignato, R. Schmitt, L. De Chiffre, and A. Weckenmann, "Computed tomography for dimensional metrology," CIRP Annals, vol. 60, no. 2, pp. 821-842, 2011.

[66] X. Chen, G. Chen, and F. Gao, "Capacitive transducer for inmold monitoring of injection molding," Polymer Engineering And Science, vol. 44, no. 8, pp. 1571-1578, 2004.

[67] K. T. Fung, F. Gao, and X. Chen, "Application of a capacitive transducer for online part weight prediction and fault detection in injection molding," Polymer Engineering \& Science, vol. 47, no. 4, pp. 347-353, 2007.

[68] H. Y. Wong, K. T. Fung, and F. Gao, "Development of a transducer for in-line and through cycle monitoring of key process and quality variables in injection molding," Sensors and Actuators A: Physical, vol. 141, no. 2, pp. 712-722, 2008.

[69] X. Chen, L. Zhang, X. Kong, J. Lu, and F. Gao, "Automatic velocity profile determination for uniform filling in injection molding," Polymer Engineering \& Science, vol. 50, no. 7, pp. 1358-1371, 2010.

[70] Y. Peng, H. Li, and L.-S. Turng, "Development of a rheodielectric sensor for online shear stress measurement during the injection molding process," Polymer Engineering \& Science, vol. 50, no. 1, pp. 61-68, 2010.

[71] A. V. Mamishev, K. Sundara-Rajan, F. Fumin Yang, Y. Yanqing $\mathrm{Du}$, and $\mathrm{M}$. Zahn, "Interdigital sensors and transducers," Proceedings of the IEEE, vol. 92, no. 5, pp. 808-845, 2004.

[72] T. Yamwong, A. M. Voice, G. R. Davies et al., "Electrostrictive response of an ideal polar rubber," Journal of Applied Physics, vol. 91, no. 3, pp. 1472-1476, 2002.

[73] Y. Zhang, Z. Huang, H. Zhou, and X. Gao, "Capacitance to digital converter method for dielectrostriction of polymeric materials," in Proceedings of the Annual Technical Conference-ANTEC Indianapolis, pp. 1497-1501, Indianapolis, IN, USA, May 2016.

[74] V. Nagarajan, K. Zhang, M. Misra, and A. K. Mohanty, "Overcoming the fundamental challenges in improving the impact strength and crystallinity of PLA biocomposites: influence of nucleating agent and mold temperature," ACS Applied Materials \& Interfaces, vol. 7, no. 21, pp. 1120311214, 2015.

[75] J. Anakabe, A. M. Zaldua Huici, A. Eceiza, A. Arbelaiz, and L. Avérous, "Combined effect of nucleating agent and plasticizer on the crystallization behaviour of polylactide," Polymer Bulletin, vol. 74, no. 12, pp. 4857-4886, 2017.

[76] M. R. Kamal, R. El Otmani, A. Derdouri, and J.-S. Chu, "Flow and thermal history effects on morphology and tensile behavior of poly(oxymethylene) micro injection molded parts," International Polymer Processing, vol. 32, no. 5, pp. 590-605, 2017.

[77] M. Rinaldi, D. Puglia, F. Dominici, V. Cherubini, L. Torre, and F. Nanni, "Melt processing and mechanical property characterization of high-performance poly(ether ether ketone)-carbon nanotube composite," Polymer International, vol. 66, no. 12, pp. 1731-1736, 2017.

[78] S. J. A. Rizvi, "Effect of injection molding parameters on crystallinity and mechanical properties of isotactic polypropylene," International Journal Of Plastics Technology, vol. 21, no. 2, pp. 404-426, 2017.

[79] M. Zhou, D. Mi, F. Hou, and J. Zhang, "Insight into understanding the evolution of the epitaxy crystallization in isotactic polypropylene and polyethylene blends," Polymers for Advanced Technologies, vol. 28, no. 12, pp. 1750-1758, 2017.
[80] X. Tardif, B. Pignon, N. Boyard et al., "Experimental study of crystallization of PolyEtherEtherKetone (PEEK) over a large temperature range using a nano-calorimeter," Polymer Testing, vol. 36, pp. 10-19, 2014.

[81] K. A. Mirica, S. S. Shevkoplyas, S. T. Phillips, M. Gupta, and G. M. Whitesides, "Measuring densities of solids and liquids using magnetic levitation: fundamentals," Journal of the American Chemical Society, vol. 131, no. 29, pp. 1004910058, 2009.

[82] J. Xie, P. Zhao, Z. Jing, C. Zhang, N. Xia, and J. Fu, "Research on the sensitivity of magnetic levitation (MagLev) devices," Journal of Magnetism and Magnetic Materials, vol. 468, pp. 100-104, 2018.

[83] C. Zhang, P. Zhao, J. Xie, N. Xia, and J. Fu, "Enlarging density measurement range for polymers by horizontal magneto-Archimedes levitation," Polymer Testing, vol. 67, pp. 177-182, 2018.

[84] X. Zhang, F. Gu, J. Xie, C. Zhang, J. Fu, and P. Zhao, "Magnetic projection: a novel separation method and its first application on separating mixed plastics," Waste Management, vol. 87, pp. 805-813, 2019.

[85] A. Winkleman, R. Perez-Castillejos, K. L. Gudiksen, S. T. Phillips, M. Prentiss, and G. M. Whitesides, "Densitybased diamagnetic separation: devices for detecting binding events and for collecting unlabeled diamagnetic particles in paramagnetic solutions," Analytical Chemistry, vol. 79, no. 17, pp. 6542-6550, 2007.

[86] Q.-H. Gao, W.-M. Zhang, H.-X. Zou et al., "Tunable rotating-mode density measurement using magnetic levitation," Applied Physics Letters, vol. 112, no. 14, Article ID 142408, 2018.

[87] K. A. Mirica, S. T. Phillips, S. S. Shevkoplyas, and G. M. Whitesides, "Using magnetic levitation to distinguish atomic-level differences in chemical composition of polymers, and to monitor chemical reactions on solid supports," Journal of the American Chemical Society, vol. 130, no. 52, pp. 17678-17680, 2008.

[88] A. Nemiroski, S. Soh, S. W. Kwok, H.-D. Yu, and G. M. Whitesides, "Tilted magnetic levitation enables measurement of the complete range of densities of materials with low magnetic permeability," Journal of the American Chemical Society, vol. 138, no. 4, pp. 1252-1257, 2016.

[89] J. Xie, P. Zhao, C. Zhang, Y. Hao, N. Xia, and J. Fu, “A feasible, portable and convenient density measurement method for minerals via magnetic levitation," Measurement, vol. 136, pp. 564-572, 2019.

[90] C. Zhang, P. Zhao, F. Gu et al., "Single-ring magnetic levitation configuration for object manipulation and densitybased measurement," Analytical Chemistry, vol. 90, no. 15, pp. 9226-9233, 2018.

[91] C. Zhang, P. Zhao, D. Tang et al., "Axial magnetic levitation: a high-sensitive and maneuverable density-based analysis device," Sensors and Actuators B: Chemical, vol. 304, no. 1, Article ID 127362, 2020.

[92] A. B. Subramaniam, D. Yang, H.-D. Yu et al., "Noncontact orientation of objects in three-dimensional space using magnetic levitation," Proceedings of the National Academy of Sciences, vol. 111, no. 36, pp. 12980-12985, 2014.

[93] J. W. Hennek, A. Nemiroski, A. B. Subramaniam et al., "Using magnetic levitation for non-destructive quality control of plastic parts," Advanced Materials, vol. 27, no. 9, pp. 1587-1592, 2015.

[94] N. Xia, P. Zhao, J. Xie, C. Zhang, and J. Fu, "Non-destructive measurement of three-dimensional polymeric parts by 
magneto-Archimedes levitation," Polymer Testing, vol. 66, pp. 32-40, 2018.

[95] N. Xia, P. Zhao, J. Xie, C. Zhang, J. Fu, and L.-S. Turng, "Defect diagnosis for polymeric samples via magnetic levitation," NDT \& E International, vol. 100, pp. 175-182, 2018.

[96] P. Zhao, J. Xie, J. Zhang, C. Zhang, N. Xia, and J. Fu, "Evaluation of polymer injection molded parts via densitybased magnetic levitation," Journal of Applied Polymer Science, vol. 137, no. 7, Article ID 48431, 2020.

[97] M. B. J. Atkinson, D. K. Bwambok, J. Chen et al., "Using magnetic levitation to separate mixtures of crystal polymorphs," Angewandte Chemie International Edition, vol. 52, no. 39, pp. 10208-10211, 2013.

[98] P. Zhao, J. Xie, F. Gu, N. Sharmin, P. Hall, and J. Fu, "Separation of mixed waste plastics via magnetic levitation," Waste Management, vol. 76, pp. 46-54, 2018.

[99] D. Kramar and D. Cica, "Predictive model and optimization OF processing parameters for plastic injection moulding," Materiali in Tehnologije, vol. 51, no. 4, pp. 597-602, 2017.

[100] C. C. Kuo and H. Y. Liao, "Dimensional accuracy optimization of the micro-plastic injection molding process using the Taguchi design method," Materials Science, vol. 21, no. 2, pp. 244-248, 2015.

[101] C.-M. Lin and H.-K. Hsieh, "Processing optimization of Fresnel lenses manufacturing in the injection molding considering birefringence effect," Microsystem Technologies, vol. 23, no. 12, pp. 5689-5695, 2017.

[102] C. Kim and J. Park, "Optimization of an injection molding process for polycarbonate car switch buttons using the Taguchi method," Composites Research, vol. 29, no. 1, pp. 7-15, 2016.

[103] M. D. Azaman, S. M. Sapuan, S. Sulaiman, E. S. Zainudin, and A. Khalina, "Optimization and numerical simulation analysis for molded thin-walled parts fabricated using woodfilled polypropylene composites via plastic injection molding," Polymer Engineering and Science, vol. 55, no. 5, pp. 1082-1095, 2015.

[104] T. Wen, X. Chen, C. Yang, L.-T. Liu, and L. Hao, "Optimization of processing parameters for minimizing warpage of large thin-walled parts in whole stages of injection molding," Chinese Journal of Polymer Science, vol. 32, no. 11, pp. 1535-1543, 2014.

[105] H. Pervez, M. S. Mozumder, and A. H. I. Mourad, "Optimization of injection molding parameters for HDPE/TiO2 nanocomposites fabrication with multiple performance characteristics using the Taguchi method and grey relational analysis," Materials, vol. 9, no. 8, p. 12, 2016.

[106] X. C. Xie, C. G. Lin, C. G. H. Jia, and R. J. Cao, "Optimization of injection molding process parameters for ultrafinegrained WC-6Co cemented carbide," Rare Metal Materials and Engineering, vol. 44, no. 12, pp. 3202-3207, 2015.

[107] S. Yu, Y. Zhang, D. Yang, H. Zhou, and J. Li, "Offline prediction of process windows for robust injection molding," Journal of Applied Polymer Science, vol. 131, no. 18, 2014.

[108] Y.-Q. Wang, J.-G. Kim, and J.-I. Song, "Optimization of plastic injection molding process parameters for manufacturing a brake booster valve body," Materials and Design (1980-2015), vol. 56, pp. 313-317, 2014.

[109] M. A. Barghash and F. A. Alkaabneh, "Shrinkage and warpage detailed analysis and optimization for the injection molding process using multistage experimental design," Quality Engineering, vol. 26, no. 3, pp. 319-334, 2014.

[110] Y. Wang, Z. Yan, and X. Shan, "Optimization of process parameters for vertical-faced polypropylene bottle injection molding," Advances in Materials Science and Engineering, vol. 2018, p. 9, 2018.

[111] B. Kc, O. Faruk, J. A. M. Agnelli, A. L. Leao, J. Tjong, and M. Sain, "Sisal-glass fiber hybrid biocomposite: optimization of injection molding parameters using Taguchi method for reducing shrinkage," Composites Part A: Applied Science and Manufacturing, vol. 83, pp. 152-159, 2016.

[112] Y.-T. Jou, W.-T. Lin, W.-C. Lee, and T.-M. Yeh, "Integrating the Taguchi method and response surface methodology for process parameter optimization of the injection molding," Applied Mathematics and Information Sciences, vol. 8, no. 3, pp. 1277-1285, 2014.

[113] E. Oliaei, B. S. Heidari, S. M. Davachi et al., "Warpage and shrinkage optimization of injection-molded plastic spoon parts for biodegradable polymers using Taguchi, ANOVA and artificial neural network methods," Journal of Materials Science and Technology, vol. 32, no. 8, pp. 710-720, 2016.

[114] X. Sánchez-Sánchez, A. Elias-Zuñiga, and M. HernándezAvila, "Processing of ultra-high molecular weight polyethylene/graphite composites by ultrasonic injection moulding: Taguchi optimization," Ultrasonics Sonochemistry, vol. 44, pp. 350-358, 2018.

[115] G. Singh, M. K. Pradhan, and A. Verma, "Multi Response optimization of injection moulding Process parameters to reduce cycle time and warpage," Materials Today: Proceedings, vol. 5, no. 2, pp. 8398-8405, 2018.

[116] J. Zhang, X. Yin, F. Liu, and P. Yang, "The simulation of the warpage rule of the thin-walled part of polypropylene composite based on the coupling effect of mold deformation and injection molding process," Science and Engineering of Composite Materials, vol. 25, no. 3, pp. 593-601, 2018.

[117] F. Zhao, N. Lu, and J. Lu, "Quality control of batch processes using natural gradient based model-free optimization," IFAC Proceedings Volumes, vol. 47, no. 3, pp. 8335-8340, 2014.

[118] W. Guo, L. Hua, and H. Mao, "Minimization of sink mark depth in injection-molded thermoplastic through design of experiments and genetic algorithm," International Journal of Advanced Manufacturing Technology, vol. 72, no. 1-4, pp. 365-375, 2014.

[119] H. Shi, Y. Gao, and X. Wang, "Optimization of injection molding process parameters using integrated artificial neural network model and expected improvement function method," International Journal of Advanced Manufacturing Technology, vol. 48, no. 9-12, pp. 955-962, 2010.

[120] W. Xia, B. Luo, and X. P. Liao, “An enhanced optimization approach based on Gaussian process surrogate model for process control in injection molding," International Journal of Advanced Manufacturing Technology, vol. 56, no. 9-12, pp. 929-942, 2011.

[121] F. Gu, P. Hall, N. J. Miles, Q. Ding, and T. Wu, "Improvement of mechanical properties of recycled plastic blends via optimizing processing parameters using the Taguchi method and principal component analysis," Materials and Design (1980-2015), vol. 62, pp. 189-198, 2014.

[122] A. Asfaram, M. Ghaedi, and S. Hajati, "Screening and optimization of highly effective ultrasound-assisted simultaneous adsorption of cationic dyes onto $\mathrm{Mn}$-doped $\mathrm{Fe}_{3} \mathrm{O}_{4}{ }^{-}$ nanoparticle-loaded activated carbon," Ultrasonics Sonochemistry, vol. 34, pp. 1-12, 2016.

[123] K. Li, S. L. Yan, W. F. Pan, and G. Zhao, "Warpage optimization of fiber-reinforced composite injection molding by combining back propagation neural network and genetic algorithm," The International Journal of Advanced 
Manufacturing Technology, vol. 90, no. 1-4, pp. 963-970, 2017.

[124] S. J. A. Rizvi, A. K. Singh, and G. R. Bhadu, "Optimization of tensile properties of injection molded $\alpha$-nucleated polypropylene using response surface methodology," Polymer Testing, vol. 60, pp. 198-210, 2017.

[125] B. S. Heidari, E. Oliaei, H. Shayesteh et al., "Simulation of mechanical behavior and optimization of simulated injection molding process for PLA based antibacterial composite and nanocomposite bone screws using central composite design," Journal of the Mechanical Behavior of Biomedical Materials, vol. 65, pp. 160-176, 2017.

[126] S. M. S. Mukras, H. M. Omar, and F. A. al-Mufadi, "Experimental-based multi-objective optimization of injection molding process parameters," Arabian Journal for Science and Engineering, vol. 44, no. 9, pp. 7653-7665, 2019.

[127] H.-G. Kim, H. J. Son, D.-K. Lee, D.-W. Kim, H. J. Park, and D.-H. Cho, "Optimization and analysis of reaction injection molding of polydicyclopentadiene using response surface methodology," Korean Journal of Chemical Engineering, vol. 34, no. 7, pp. 2099-2109, 2017.

[128] S. Kitayama, H. Miyakawa, M. Takano, and S. Aiba, "Multiobjective optimization of injection molding process parameters for short cycle time and warpage reduction using conformal cooling channel," The International Journal of Advanced Manufacturing Technology, vol. 88, no. 5-8, pp. 1735-1744, 2017.

[129] S. Kitayama, M. Yokoyama, M. Takano, and S. Aiba, "Multiobjective optimization of variable packing pressure profile and process parameters in plastic injection molding for minimizing warpage and cycle time," The International Journal of Advanced Manufacturing Technology, vol. 92, no. 9-12, pp. 3991-3999, 2017.

[130] S. Kitayama and S. Natsume, "Multi-objective optimization of volume shrinkage and clamping force for plastic injection molding via sequential approximate optimization," Simulation Modelling Practice and Theory, vol. 48, pp. 35-44, 2014.

[131] J. H. Zhang, J. Wang, J. W. Lin, Q. Guo, K. W. Chen, and L. Ma, "Multiobjective optimization of injection molding process parameters based on Opt LHD, EBFNN, and MOPSO," The International Journal of Advanced Manufacturing Technology, vol. 85, no. 9-12, pp. 2857-2872, 2016.

[132] H. Gao, Y. Zhang, X. Zhou, and D. Li, "Intelligent methods for the process parameter determination of plastic injection molding," Frontiers of Mechanical Engineering, vol. 13, no. 1, pp. 85-95, 2018.

[133] H. S. Park and T. T. Nguyen, "Optimization of injection molding process for car fender in consideration of energy efficiency and product quality," Journal of Computational Design and Engineering, vol. 1, no. 4, pp. 256-265, 2014.

[134] K. Li, S. Yan, Y. Zhong, W. Pan, and G. Zhao, "Multi-objective optimization of the fiber-reinforced composite injection molding process using Taguchi method, RSM, and NSGA-II," Simulation Modelling Practice and Theory, vol. 91, pp. 69-82, 2019.

[135] S. Kitayama, R. Onuki, and K. Yamazaki, "Warpage reduction with variable pressure profile in plastic injection molding via sequential approximate optimization," The International Journal of Advanced Manufacturing Technology, vol. 72, no. 5-8, pp. 827-838, 2014.

[136] Y. J. Xu, Q. W. Zhang, W. H. Zhang, and P. Zhang, “Optimization of injection molding process parameters to improve the mechanical performance of polymer product against impact," The International Journal of Advanced Manufacturing Technology, vol. 76, no. 9-12, pp. 2199-2208, 2015.

[137] S. Kitayama, K. Tamada, M. Takano, and S. Aiba, "Numerical and experimental investigation on process parameters optimization in plastic injection molding for weldlines reduction and clamping force minimization," The International Journal of Advanced Manufacturing Technology, vol. 97, no. 5-8, pp. 2087-2098, 2018.

[138] S. Kitayama, K. Tamada, M. Takano, and S. Aiba, "Numerical optimization of process parameters in plastic injection molding for minimizing weldlines and clamping force using conformal cooling channel," Journal of Manufacturing Processes, vol. 32, pp. 782-790, 2018.

[139] S. Kitayama, Y. Yamazaki, M. Takano, and S. Aiba, "Numerical and experimental investigation of process parameters optimization in plastic injection molding using multicriteria decision making," Simulation Modelling Practice and Theory, vol. 85, pp. 95-105, 2018.

[140] X. Y. Wang, H. X. Li, J. F. Gu et al., "Pressure analysis of dynamic injection molding and process parameter optimization for reducing warpage of injection molded products," Polymers, vol. 9, no. 3, p. 23, 2017.

[141] X. Y. Wang, J. F. Gu, C. Y. Shen, and X. C. Wang, "Warpage optimization with dynamic injection molding technology and sequential optimization method," The International Journal of Advanced Manufacturing Technology, vol. 78, no. 1-4, pp. 177-187, 2015.

[142] H. Li, K. Liu, D. Zhao, M. Wang, Q. Li, and J. Hou, "Multiobjective optimizations for microinjection molding process parameters of biodegradable polymer stent," Materials, vol. 11, no. 11, p. 2322, 2018.

[143] P. Zhao, Z. Dong, J. Zhang et al., "Optimization of injection molding process parameters for weight control: converting optimization problem to classification problem," Advances in Polymer Technology, In press, 2019.

[144] J. Zhao, Y. Yang, X. Chen, and F. Gao, "An iterative modeling and trust-region optimization method for batch processes," Industrial and Engineering Chemistry Research, vol. 54, no. 12, pp. 3186-3199, 2015.

[145] S. Zhu, Y. Yang, B. Yang, Z. Shao, and X. Chen, "Model-free quality optimization strategy for a batch process with short cycle time and low operational cost," Industrial and Engineering Chemistry Research, vol. 53, no. 42, pp. 16384-16396, 2014.

[146] J. Zhao, G. D. Cheng, S. L. Ruan, and Z. Li, "Multi-objective optimization design of injection molding process parameters based on the improved efficient global optimization algorithm and non-dominated sorting-based genetic algorithm," The International Journal of Advanced Manufacturing Technology, vol. 78, no. 9-12, pp. 1813-1826, 2015.

[147] W. C. Chen, P. H. Liou, and S. C. Chou, "An integrated parameter optimization system for MIMO plastic injection molding using soft computing," The International Journal of Advanced Manufacturing Technology, vol. 73, no. 9-12, pp. 1465-1474, 2014.

[148] G.-J. Kang, C.-H. Park, and D.-H. Choi, "Metamodel-based design optimization of injection molding process variables and gates of an automotive glove box for enhancing its quality," Journal of Mechanical Science and Technology, vol. 30, no. 4, pp. 1723-1732, 2016.

[149] J. H. Liu, X. D. Chen, Z. Q. Lin, and S. P. Diao, "Multiobjective optimization of injection molding process 
parameters for the precision manufacturing of plastic optical lens," Mathematical Problems in Engineering, vol. 2017, p. 13, 2017.

[150] M. Tian, X. Gong, L. Yin et al., "Multi-objective optimization of injection molding process parameters in two stages for multiple quality characteristics and energy efficiency using Taguchi method and NSGA-II," The International Journal of Advanced Manufacturing Technology, vol. 89, no. 1-4, pp. 241-254, 2017.

[151] K. Li, S. L. Yan, W. F. Pan, and G. Zhao, "Optimization of fiber-orientation distribution in fiber-reinforced composite injection molding by Taguchi, back propagation neural network, and genetic algorithm-particle swarm optimization," Advances in Mechanical Engineering, vol. 9, no. 9, p. 11, 2017.

[152] W. C. Chen, M. H. Nguyen, W. H. Chiu, T. N. Chen, and P. H. Tai, "Optimization of the plastic injection molding process using the Taguchi method, RSM, and hybrid GAPSO," The International Journal of Advanced Manufacturing Technology, vol. 83, no. 9-12, pp. 1873-1886, 2016.

[153] W.-C. Chen and D. Kurniawan, "Process parameters optimization for multiple quality characteristics in plastic injection molding using Taguchi method, BPNN, GA, and hybrid PSO-GA," International Journal of Precision Engineering and Manufacturing, vol. 15, no. 8, pp. 1583-1593, 2014.

[154] C.-M. Lin and Y.-W. Chen, "Grey optimization of injection molding processing of plastic optical lens based on joint consideration of aberration and birefringence effects," Microsystem Technologies, vol. 25, no. 2, pp. 621-631, 2019.

[155] R. J. Bensingh, R. Machavaram, S. R. Boopathy, and C. Jebaraj, "Injection molding process optimization of a biaspheric lens using hybrid artificial neural networks (ANNs) and particle swarm optimization (PSO)," Measurement, vol. 134, pp. 359-374, 2019.

[156] J. L. Kuo and M. T. Chang, "Multiobjective design of turbo injection mode for axial flux motor in plastic injection molding machine by particle swarm optimization," Mathematical Problems in Engineering, vol. 2015, p. 11, 2015.

[157] G. Xu and Z. T. Yang, "Multiobjective optimization of process parameters for plastic injection molding via soft computing and grey correlation analysis," The International Journal of Advanced Manufacturing Technology, vol. 78, no. 1-4, pp. 525-536, 2015.

[158] R. Eberhart and J. Kennedy, "Particle swarm optimization," in Proceeding of IEEE International Conference on Neural Network, pp. 1942-1948, Perth, Australia, November 1995.

[159] T. Weise, Global Optimization Algorithms-Theory and Application, 2009.

[160] S. Johnston, C. McCready, D. Hazen, D. VanDerwalker, and D. Kazmer, "On-line multivariate optimization of injection molding," Polymer Engineering and Science, vol. 55, no. 12, pp. 2743-2750, 2015.

[161] Y. Yang, B. Yang, S. Zhu, and X. Chen, "Online quality optimization of the injection molding process via digital image processing and model-free optimization," Journal of Materials Processing Technology, vol. 226, pp. 85-98, 2015.

[162] Y. Yang and F. Gao, "Adaptive control of the filling velocity of thermoplastics injection molding," Control Engineering Practice, vol. 8, no. 11, pp. 1285-1296, 2000.

[163] B. Yang, Z. Xu, Y. Yang, and F. Gao, "Application of twodimensional predictive functional control in injection molding," Industrial and Engineering Chemistry Research, vol. 54, no. 41, pp. 10088-10102, 2015.
[164] L. Wang, S. Mo, D. Zhou, F. Gao, and X. Chen, "Delayrange-dependent method for iterative learning fault-tolerant guaranteed cost control for batch processes," Industrial and Engineering Chemistry Research, vol. 52, no. 7, pp. 2661-2671, 2013.

[165] L. Wang, S. Mo, D. Zhou, F. Gao, and X. Chen, "Delayrange-dependent robust $2 \mathrm{D}$ iterative learning control for batch processes with state delay and uncertainties," Journal of Process Control, vol. 23, no. 5, pp. 715-730, 2013.

[166] R. Zhang, H. Zou, A. Xue, and F. Gao, "GA based predictive functional control for batch processes under actuator faults," Chemometrics and Intelligent Laboratory Systems, vol. 137, pp. 67-73, 2014.

[167] X. Hu, L. Wang, and F. Gao, "Genetic-algorithm-optimization-based infinite horizon linear quadratic control for injection molding batch processes with uncertainty," Industrial and Engineering Chemistry Research, vol. 57, no. 51, pp. 17462-17469, 2018.

[168] L. Wang, F. Liu, J. Yu, P. Li, R. Zhang, and F. Gao, "Iterative learning fault-tolerant control for injection molding processes against actuator faults," Journal of Process Control, vol. 59, pp. 59-72, 2017

[169] L. Wang, X. Chen, and F. Gao, "An LMI method to robust iterative learning fault-tolerant guaranteed cost control for batch processes," Chinese Journal of Chemical Engineering, vol. 21, no. 4, pp. 401-411, 2013.

[170] R. Zhang, R. Lu, A. Xue, and F. Gao, "Predictive functional control for linear systems under partial actuator faults and application on an injection molding batch process," Industrial and Engineering Chemistry Research, vol. 53, no. 2, pp. 723-731, 2014.

[171] L. Wang, S. Mo, D. Zhou, F. Gao, and X. Chen, "Robust delay dependent iterative learning fault-tolerant control for batch processes with state delay and actuator failures," Journal of Process Control, vol. 22, no. 7, pp. 1273-1286, 2012.

[172] L. Wang, S. Mo, D. Zhou, and F. Gao, "Robust design of feedback integrated with iterative learning control for batch processes with uncertainties and interval time-varying delays," Journal of Process Control, vol. 21, no. 7, pp. 987-996, 2011.

[173] R. Zhang, J. Lu, H. Qu, and F. Gao, "State space model predictive fault-tolerant control for batch processes with partial actuator failure," Journal of Process Control, vol. 24, no. 5, pp. 613-620, 2014.

[174] Z. Cao, Y. Yang, J. Lu, and F. Gao, "Two-time-dimensional model predictive control of weld line positioning in Bi-injection molding," Industrial and Engineering Chemistry Research, vol. 54, no. 17, pp. 4795-4804, 2015.

[175] R. Zhang and F. Gao, "Two-dimensional iterative learning model predictive control for batch processes: a new state space model compensation approach," IEEE Transactions on Systems, Man, and Cybernetics: Systems, pp. 1-9, 2018.

[176] B.-H. Jeong, N.-H. Kim, and K.-Y. Lee, "Optimized digital proportional integral derivative controller for heating and cooling injection molding system," Journal of Electrical Engineering and Technology, vol. 10, no. 3, pp. 1383-1388, 2015.

[177] C.-J. Chen, K.-T. Wu, and S.-J. Hwang, "Development of a servo-hydraulic system with a self-tuning fuzzy PID controller to simulate injection molding process," Microsystem Technologies, pp. 1-22, 2018.

[178] R. Dubay, B. Hu, J. M. Hernandez, and M. Charest, "Controlling process parameters during plastication in plastic injection molding using model predictive control," Advances in Polymer Technology, vol. 33, p. 8, 2014. 
[179] Y.-g. Peng, J. Wang, and W. Wei, "Model predictive control of servo motor driven constant pump hydraulic system in injection molding process based on neurodynamic optimization," Journal of Zhejiang University Science C, vol. 15, no. 2, pp. 139-146, 2014.

[180] S. Zhang, R. Dubay, and M. Charest, "A principal component analysis model-based predictive controller for controlling part warpage in plastic injection molding," Expert Systems with Applications, vol. 42, no. 6, pp. 2919-2927, 2015.

[181] C. Hopmann, A. Ressmann, M. Reiter, S. Stemmler, and D. Abel, "A self-optimising injection moulding process with model-based control system parameterisation," International Journal of Computer Integrated Manufacturing, vol. 29, no. 11, pp. 1190-1199, 2016.

[182] M. Reiter, S. Stemmler, C. Hopmann, A. Ressmann, and D. Abel, "Model predictive control of cavity pressure in an injection moulding process," IFAC Proceedings Volumes, vol. 47, no. 3, pp. 4358-4363, 2014.

[183] X. Hu, H. Zou, and L. Wang, "Design of the linear quadratic structure based predictive functional control for industrial processes against partial actuator failures using GA optimization," International Journal of Control, Automation and Systems, vol. 17, no. 3, pp. 597-605, 2019.

[184] F. Qi, S. Li, Y. Zhou, and Z. Zhou, Design of Servo Control System of Precision Injection for Electro-Hydraulic Hybrid Injection Machine, Springer, Berlin, Germany, 2014.

[185] C. Hopmann and J. Heinisch, "Process control strategies for injection molding processes with changing raw material viscosity," Journal of Polymer Engineering, vol. 38, no. 5, pp. 483-492, 2017.

[186] S. Kanagalakshmi, D. Manamalli, and M. Mohamedrafiq, "Implementation of multimodel-based PID and intelligent controller for simulated and real-time temperature control of injection molding machine," Chemical Engineering Communications, vol. 203, no. 4, pp. 452-462, 2016.

[187] C. Hopmann, D. Abel, J. Heinisch, and S. Stemmler, "Selfoptimizing injection molding based on iterative learning cavity pressure control," Production Engineering, vol. 11, no. 2, pp. 97-106, 2017.

[188] D. Dorner, T. Radermacher, B. Wagner, and J. Weber, "Iterative learning control of a plastic injection moulding machine," at-Automatisierungstechnik, vol. 62, no. 3, pp. 226-236, 2014.

[189] R. Zhang, S. Wu, and J. Tao, "A new design of predictive functional control strategy for batch processes in the twodimensional framework," IEEE Transactions on Industrial Informatics, vol. 15, no. 5, pp. 2905-2914, 2019.

[190] Y. Yang, X. Chen, N. Lu, and F. Gao, Injection Molding Process Control, Monitoring, and Optimization, Carl Hanser Verlag GmbH Co KG, Munich, Germany, 2016.

[191] V. Mnih, K. Kavukcuoglu, D. Silver et al., "Human-level control through deep reinforcement learning," Nature, vol. 518, no. 7540, pp. 529-533, 2015.

[192] Y. Ruan, Y. Zhang, T. Mao, X. Zhou, D. Li, and H. Zhou, "Trajectory optimization and positioning control for batch process using learning control," Control Engineering Practice, vol. 85, pp. 1-10, 2019. 